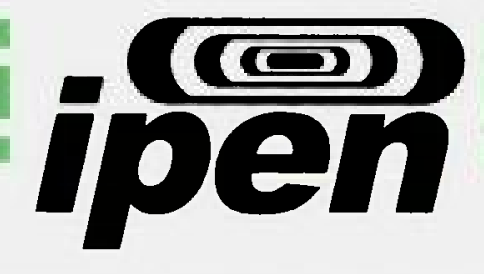

AUTARQUIA ASSOCIADA A UNIVERSIDADE DE SÃO PAULO

\title{
ESTUDO DA CARACTERIZAÇÃO DE ESPUMAS DE POLIETILENO RETICULADO PELO PROCESSO DE IRRADIAÇÃO COM FEIXE DE ELÉTRONS
}

\section{DJALMA BATISTA DIAS}

Dissertação apresentada como parte dos requisitos para obtenção do Grau de Mestre em Ciências na Área de Tecnologia Nuclear - Aplicações.

Orientador:

Dr. Leonardo Gondim de Andrade e Silva

\section{São Paulo}

2007 
INSTITUTO DE PESQUISAS ENERGÉTICAS E NUCLEARES

Autarquia Associada à Universidade de São Paulo

\section{ESTUDO DA CARACTERIZAÇÃO DE ESPUMAS DE POLIETILENO RETICULADO PELO PROCESSO DE IRRADIAÇÃO COM FEIXE DE ELÉTRONS}

\section{DJALMA BATISTA DIAS}

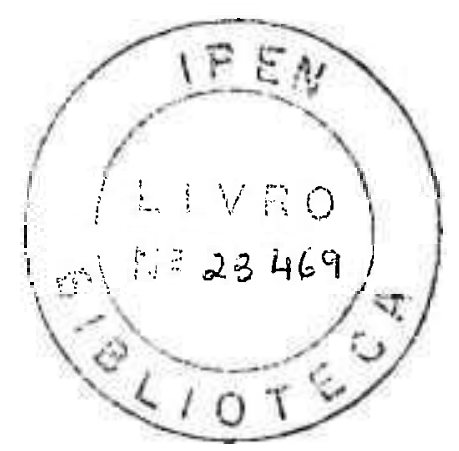

Dissertação apresentada como parte dos requisitos para obtenção do Grau de Mestre em Ciências na Área de Tecnologia Nuclear - Aplicações.

Orientador:

Dr. Leonardo Gondim de Andrade e Silva 
À Deus, por tudo o que sou.

À minha mãe, Joana Batista Dias, pelo exemplo, por tudo o que fez por mim, por suas orações, pelo apoio e estímulo.

Ả minha esposa, Ana Célia, pela compreensão, paciência e carinho. À minha filha Bianca, mais um presente de Deus. 


\section{AGRADECIMENTOS}

Desejo agradecer a todos que ajudaram na realização deste trabalho, em especial:

- Ao Dr. Leonardo Gondim de Andrade e Silva, pela especial atenção e paciência no desenvolvimento deste trabalho, desde a idéia inicial até a conclusão.

- Ao Dr. Eddy Segura Pino, pelas inúmeras contribuições e sugestões.

- À Dra. Luci Diva Brocardo, pelo apoio concedido e encorajamento.

- Ao IPEN, pela oportunidade concedida.

- Ao CTR, pelo apoio e condições para o desenviolvimento deste trabalho.

- Aos colegas do Laboratório de Fontes Intensas do CTR pelas irradiações das amostras.

- Ao Dr. Hélio Wiebeck, da Escola Politécnica da Universidade de São Paulo.

- À Dra. Leila Figueiredo, da Universidade Presbiteriana Mackenzie, pelo apoio.

- Ao Eng. Delmo Nishitsuji, do Centro de Tecnologia da Marinha - CTMSP.

- À Dra. Duclerc Fernandes Parra do CQMA-IPEN.

- Ao Técnico Vagner Fernandes do CTR, pela disposição em colaborar na confecção de acessórios necessários para a realização deste trabalho. 
Tudo tem o seu tempo determinado, e há tempo para todo propósito debaixo do céu.

Eclesiastes 3:1 


\title{
ESTUDO DA CARACTERIZAÇÃO DE ESPUMAS DE POLIETILENO RETICULADO PELO PROCESSO DE IRRADIAÇÃO COM FEIXE DE ELÉTRONS
}

\author{
Djalma Batista Dias
}

\begin{abstract}
RESUMO
As espumas de polietileno são amplamente utilizadas. Suas aplicações vão de aparelhos domésticos a artefatos médicos, incluindo aplicações nas indústrias de construção civil e automobilística. As propriedades das espumas dependem da densidade e da sua estrutura celular, em outras palavras, da quantidade de células abertas e fechadas, da distribuição e do tamanho das células. Os métodos de produção de espumas de polietileno reticulado são classificados em dois tipos, de acordo com o método de reticulação. Um dos métodos é a reticulação química, que utiliza peróxidos como agente reticulante. $\mathrm{O}$ outro método é a reticulação por irradiação, utilizando feixe de elétrons. As espumas obtidas a partir do polietileno reticulado pelo processo de irradiação apresentam superficie lisa e homogênea, e são formadas basicamente por células fechadas. $O$ objetivo deste trabalho foi utilizar a radiação ionizante para a formação de ligações cruzadas entre as moléculas de polietileno de baixa densidade (LDPE), que permitiu a obtenção das espumas. As suas propriedades mecânicas, térmicas e morfológicas foram avaliadas. As amostras de polietileno com densidade de $0,946 \mathrm{~g} / \mathrm{cm}^{3}$, contendo $5 \%$ de azodicarbonamida (ADCA), agente expansor, foram irradiadas com feixe de elétrons de alta energia com doses de radiação de 10,20,30,40,50,60,80 e 100 kGy. Após a irradiação, as amostras de LDPE foram colocadas em um forno para expansão térmica e formação das espumas. Foi determinado o grau de reticulação das espumas. Algumas amostras também foram envelhecidas termicamente. $O$ desempenho mecânico das amostras de espumas foi avaliado por meio de ensaios de tração e deformação, dureza, deformação permanente por compressão e resiliência. Também foram realizados ensaios de termogravimetria (TGA) e de microscopia eletrônica de varredura (MEV). Os resultados mostraram que no intervalo de doses de radiação estudadas, a resistência à tração aumenta com o aumento do grau de reticulação. Nos ensaios de resistência à compressão, a partir da dose de radiação de 40 kGy, observou-se um decréscimo nos valores obtidos. Já a resiliência sofreu pouca alteração. De acordo com a análise morfológica pode-se concluir que a dose de radiação de $30 \mathrm{kGy}$ foi a que promoveu a formação de espumas com estrutura celular fechada e mais homogênea.
\end{abstract}




\title{
STUDY OF THE CARACTERIZATION OF CROSSLINKING POLYETHYLENE FOAM BY IRRADIATION PROCESS WITH ELECTRON BEAM
}

\author{
Djalma Batista Dias
}

\begin{abstract}
The polyethylene foams are widely used. Their main applications are used for both home appliances to medical equipments. Beside that, they have applications in building and automotive industries. The foam properties depend on the density and its cellular structure, that is, the amount of open and closed cells, of the distribution and size of them. The methods of the crosslinking polyethylene foam production are classified in two types, according to the crosslinking method. One method is based on the chemical crosslinking, which utilizes peroxide as crosslinking agent. In the other method, the crosslinking is induced by electron beam radiation. The foams obtained from the crosslinking polyethylene by irradiation process presented a smooth and the homogeneous surface, and are formed basically by closed cells. The aim of this study was to apply the ionizing radiation from electron beam to crosslink low density polyethylene (LDPE), to obtain foams. Their morphological, thermal and mechanical properties were studied to evaluate the obtained samples. The samples of low density polyethylene $\left(0,946 \mathrm{~g} / \mathrm{cm}^{3}\right)$, containing $5 \%$ of azodicarbonamide (ADCA), as expander agent, were irradiated with electron beam with doses of 10,20,30,40,50,60,80 and $100 \mathrm{kGy}$. After the irradiation, these LDPE samples were put into an oven to obtain the foams. It was determined the crosslinking degree of the foams. Some samples were also thermically aged. The mechanical performance of the foams samples was evaluated by means of the tensile strenght, compression, hardness, permanent deformation by compression and resilience. It was also carried out thermogravimetry and scanning electron microscopy (SEM). The results have shown that, in the interval of radiation doses studied, that the tensile strength increases with the increase of the crosslinking degree. The compression resistance results obtained from with samples with to radiation dose of $40 \mathrm{kGy}$ showed significant decreasing. The resilience measurements have shown only little variations. According to the morphological analysis it can be concluded that foams with radiation dose of $30 \mathrm{kGy}$ have closed cellular structure more homogeneous and smooth morphology.
\end{abstract}




\section{SUMÁRIO}

1 INTRODUÇÃO

Página

2 OBJETIVOS

3 REVISÃO BIBLIOGRÁFICA 15

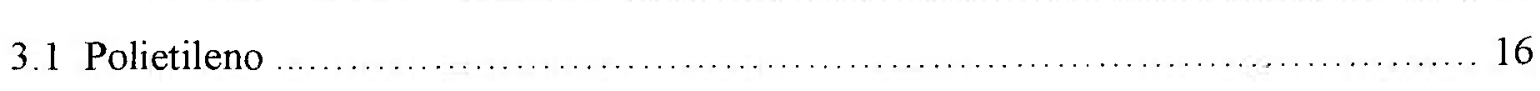

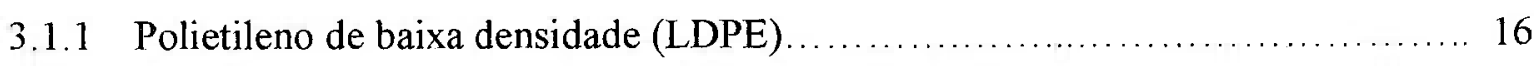

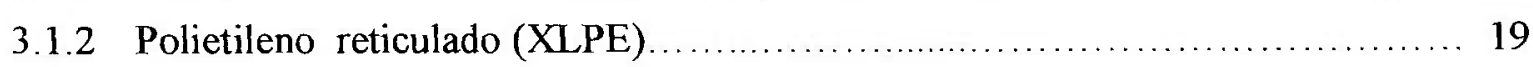

3.2 Envelhecimento artificial acelerado de polímeros ........................... 22

3.3 Espumas de polietileno............................................. 23

3.3.1 Princípios fundamentais de formação de espuma ........................... 24

3.3.1.1 Formação da bolha ............................................... 24

3.3.1.2 Crescimento da bolha............................................. 24

3.3.1.3 Estabilidade da bolha ........................................... 25

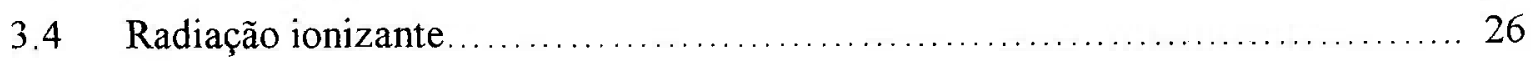

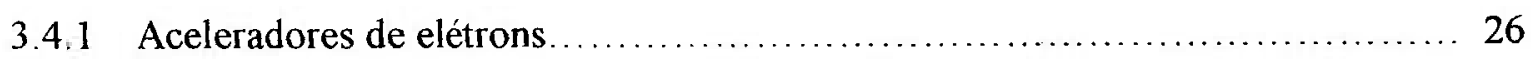

3.4 .2 Efeito da radiação ionizante em polímeros.................................. 28

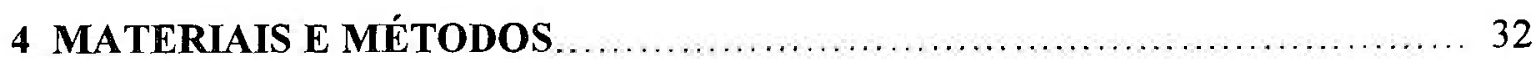

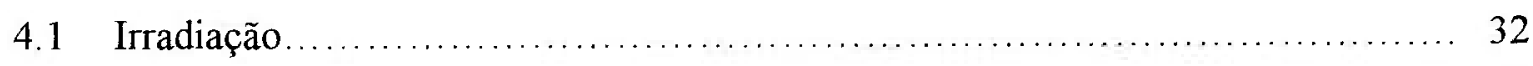

4.2 Teor de gel ou grau de reticulação ..................................... 32

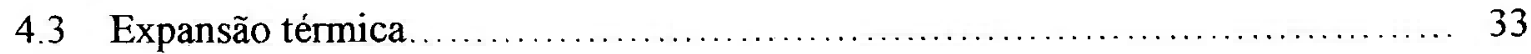

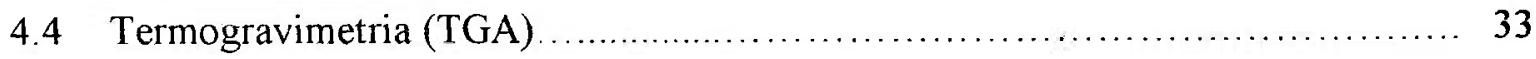

4.5 Densidade das espumas de LDPE ................................... 34

4.6 Ensaio de envelhecimento e verificação da estabilidade térmica................ 34

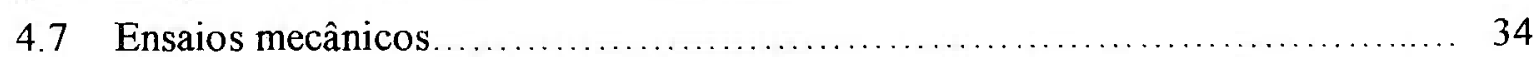

4.7.1 Resistência à tração ................................................. 34

4.7.2 Resistência à compressão ............................................. 36

4.7.3 Deformação permanente por compressão.............................. 37

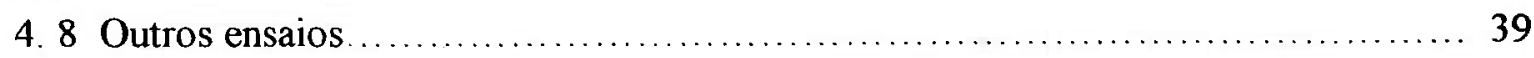

4.8.1 Determinação da dureza Shore A ..................................... 39

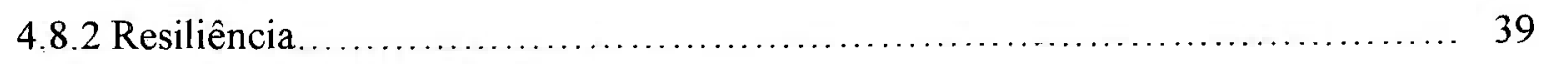




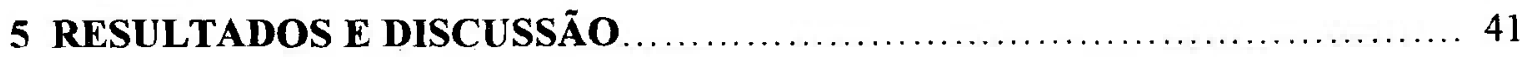

5.1 Expansão térmica .................................................... 41

5.2 Porcentagem de reticulação ........................................... 41

5.3 Estabilidade térmica das espumas...................................... 43

5.4 Ensaios de resistência à tração ......................................... 45

5.5 Ensaios de resistência à compressão ......................................... 48

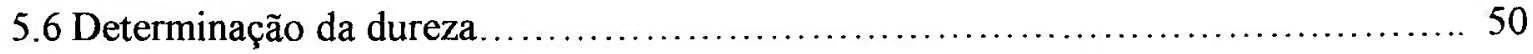

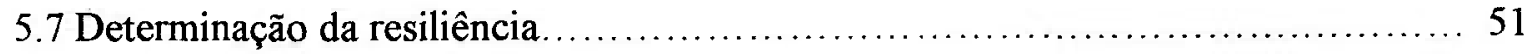

5.8 Microscopia eletrônica de varredura ..................................... 52

5.9 Ensaios de resistência à deformação permanente por compressão ................ 54

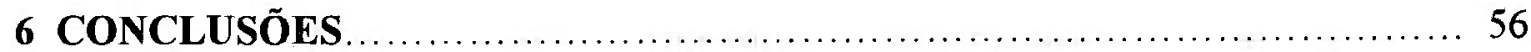

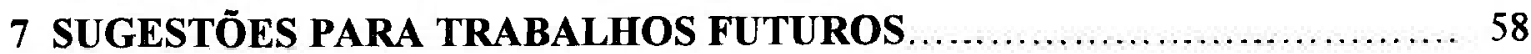

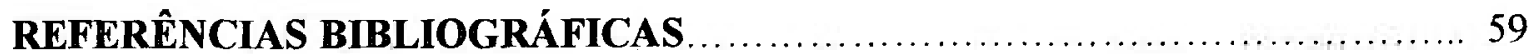




\section{LISTA DE TABELAS}

Página

TABELA 1 Tipos de espumas poliméricas e suas propriedades

TABELA 2 Fração gel das espumas de LDPE reticulado com diferentes doses de radiação e com peróxido

TABELA 3 Temperaturas de degradação de LDPE não espumado em função da dose de radiação.

TABELA 4 Variação das dimensões para verificação da estabilidade térmica das espumas de LDPE reticulado por radiação e por peróxido

TABELA 5 Resistência à tração e alongamento na ruptura de amostras de espumas de LDPE reticulado por radiação a diferentes doses e por peróxido, envelhecidas e não envelhecidas termicamente

TABELA 6 Resistência à compressão (40\% e 60\%) de amostras de espumas de LDPE reticulado por radiação a diferentes doses e por peróxido, envelhecidas e não envelhecidas termicamente.

TABELA 7 Dureza de amostras de espumas de LDPE reticulado por radiação a diferentes doses e por peróxido.

TABELA 8 Resiliência de amostras de espumas de LDPE reticulado por radiação a diferentes doses e por peróxido

TABELA 9 Deformação permanente por compressão (DPC) de espumas de LDPE reticulado por radiação a diferentes doses e por peróxido 


\section{LISTA DE FIGURAS}

Página

FIGURA 1 Diagrama do processo de formação de espumas de polietileno reticulado por feixe de elétrons.

FIGURA 2 Sistema de varredura do feixe de acelerador de elétrons do Centro de Tecnologia das Radiações do IPEN

FIGURA 3 Forno com circulação de ar

FIGURA 4 Expansão do polietileno 33

FIGURA 5 Corpos-de-prova de espumas de LDPE para ensaios de tração. 36

FIGURA 6 Equipamento para ensaios de tração e deformação do CTR no IPEN.. 36

FIGURA 7 Acessórios para ensaios de compressão na Instron. 37

FIGURA 8 Dispositivo para ensaio de deformação permanente por compressão .. 38

FIGURA 9 Amostra sob compressão 39

FIGURA 10 Resiliômetro. 40

FIGURA 11 Grau de reticulação de espumas de LDPE reticulado por feixe de elétrons a diferentes doses de radiação e por peróxido

FIGURA 12 Comportamento das espumas de LDPE reticulado por radiação a diferentes doses e por peróxido, para verificação da estabilidade térmica 44

FIGURA 13 Comportamento da resistência à tração na ruptura das espumas de 
LDPE reticulado por radiação e por peróxido, envelhecidas e não envelhecidas.

FIGURA 14 Comportamento da deformação na ruptura das espumas de LDPE reticulado por radiação e por peróxido, envelhecidas e não envelhecidas

FIGURA 15 Resistência à compressão (40\%) das espumas de LDPE reticulado, envelhecidas e não envelhecidas, em função da dose de radiação 49

FIGURA 16 Resistência à compressão (60\%) das espumas de LDPE reticulado, envelhecidas e não envelhecidas, em função da dose de radiação

FIGURA 17 Micrografia de espuma de LDPE reticulado por radiação com dose de 20 kGy (Ampliação de 15X) 52

FIGURA 18 Micrografia de espuma de LDPE reticulado por radiação com dose de 30 kGy (Ampliação de 30X).

FIGURA 19 Micrografia de espuma de LDPE reticulado por radiação com dose de 40 kGy (Ampliação de 30X).

FIGURA 20 Micrografia de espuma de LDPE reticulado por radiação com dose de 60 kGy (Ampliação de 30X).

FIGURA 21 Comportamento das espumas de LDPE reticulado por radiação e por peróxido para verificação da deformação permanente por compressão. 


\section{INTRODUÇÃO}

A história da ciência e tecnologia de espumas poliméricas iniciou-se a partir de 1920 (FRISCH, 1981). Devido as suas propriedades como isolantes térmicos e de impacto, são amplamente utilizadas em vários campos de aplicação incluindo móveis, transportes, brinquedos, artigos esportivos, sapatos, entre outros. As espumas plásticas se tornaram importantes na nossa vida diária. O mercado mundial de espumas poliméricas é estimado em cerca de 10 milhões de toneladas/ano, ou cerca de $10 \%$ da produção de plásticos. Suas aplicações vão de aparelhos domésticos a artefatos médicos, até aplicações nas indústrias de construção civil e automobilística. As espumas plásticas podem ser obtidas a partir da decomposição térmica de um agente expansor, em uma matriz polimérica (KLEMPNER e FRISCH, 1991).

Um polímero termoplástico fundido e quente, contendo um solvente volátil dissolvido sob pressão, pode "espumar" quando a pressão é reduzida. O sistema de produção de espumas poliméricas mais utilizado envolve a dispersão de um gás numa fase polimérica fluida e estabilização da espuma resultante. Na maior parte destes sistemas a espuma é expandida pelo aumento do tamanho das bolhas antes da estabilização do sistema (SHUTOV, 1991).

As poliolefinas são polímeros duros, flexíveis, resistentes a produtos químicos e a abrasão. As espumas fabricadas a partir de poliolefinas mantêm essas propriedades. Embora classificadas como espumas semi-rígidas, as espumas de poliolefinas são, em geral, firmes, e flexíveis como as espumas de poliuretario. A maioria das espumas poliolefinicas tem estrutura celular fechada, e são divididas em de alta e de baixa densidade. Considerando a sua estrutura podem ser reticuladas e não reticuladas (KLEMPNER e FRISCH, 1991).

Estas diferenças na estrutura física são responsáveis por diferentes propriedades de polímeros expandidos contendo diferentes proporções de células abertas. Em comparação com espumas poliméricas de células fechadas, espumas com células abertas têm alta capacidade de absorção de água e umidade, uma alta permeabilidade para gás e vapor. Atualmente é possível espumar virtualmente todo o material polimérico, pois muitos dos princípios básicos da tecnologia de expansão ou formação de espumas e seus processos são aplicáveis à maioria das resinas. Na TAB.1 são apresentados alguns polímeros expandidos ou espumados e suas propriedades como espumas (WU e XU, 1999). 
TABELA 1 - Tipos de espumas poliméricas e suas propriedades

\begin{tabular}{cccc}
\hline $\begin{array}{c}\text { Tipos de espumas } \\
\text { poliméricas }\end{array}$ & Estrutura celular & $\begin{array}{c}\text { Densidade } \\
\left(\mathrm{kg} / \mathrm{m}^{3}\right)\end{array}$ & $\begin{array}{c}\text { Temperatura máxima de } \\
\text { aplicą̧ão }\left({ }^{\circ} \mathrm{C}\right)\end{array}$ \\
\hline PE & Fechada & $21-800$ & 82 \\
PS & Fechada & $16-160$ & 79 \\
ABS & Fechada & $160-895$ & 82 \\
PC & Fechada & $80-1120$ & 132 \\
PVC & Fechada & $32-64$ & 93 \\
PVC & Aberta ou Fechada & $64-960$ & $62-101$ \\
\hline
\end{tabular}

A escolha do polímero a ser expandido depende principalmente das propriedades do polímero, do processo de produção da espuma e da economia do processo. Espumas de poliuretano (PU), poliestireno (PS) e policloreto de vinila (PVC), combinam excelentes propriedades fisicas e mecânicas com relativa facilidade e custo baixo do processo de produção. Aproximadamente $70-80 \%$ de toda a espuma polimérica produzida é baseada em PU, PS ou PVC (BENNING, 1986).

Nos últimos anos a produção de espumas de polietileno vem crescendo. Suas propriedades mecânicas boas e o preço baixo do polietileno são responsáveis por isto. Diversos tipos de espumas de polietileno têm muitas aplicações nos diferentes setores da indústria (RUBENS e GRIFFIN, 1962).

As propriedades destes materiais são melhoradas se ligações cruzadas forem geradas em suas estruturas moleculares (CHARLESBY, 1952). Existem dois métodos de reticulação do LDPE. No primeiro método ligações intermoleculares são formadas pela decomposição de agentes químicos, tais como os peróxidos. Neste método, a decomposição do agente expansor ocorre simultaneamente com a expansão. No segundo método, uma estrutura tridimensional é formada pela irradiação da amostra, onde a reticulação e a expansão são estágios completamente separados.

A interação da radiação ionizante com materiais poliméricos transfere energia aos materiais, provocando principalmente a excitação e a ionização das moléculas, gerando reações químicas que podem provocar modificações permanentes na estrutura fisicoquímica dos polímeros (CORISHI, 1992). As modificações induzidas podem resultar na degradação do material polimérico ou na melhoria de suas propriedades. 
Outras modificações podem ser realizadas a partir do envelhecimento acelerado. O processo de envelhecimento envolve vários mecanismos simultâneos e aparentemente independentes e por isso o acompanhamento da evolução de determinada variável com o tempo não descreve adequadamente o comportamento da amostra frente à condições de envelhecimento acelerado. Durante a exposição podem ocorrer fenômenos como variações na cristalinidade, cisão de cadeias, reticulação e oxidação, para citar os mais relevantes. Este conjunto de variações estruturais e morfológicas torna o estudo particularmente complexo e muitas vezes o acesso a cada uma das variáveis separadamente é extremamente dificil, e pode ainda não reproduzir os efeitos esperados. Neste trabalho foi apresentada, inicialmente, uma revisão bibliográfica abordando aspectos do polímero utilizado como matéria-prima, do material reticulado, do material expandido ou espuma, do envelhecimento acelerado de polímeros em equipamentos e de trabalhos publicados correlacionados com o estudo aqui descrito. Em seguida foi feita a descrição dos materiais e metodologias empregadas, os resultados obtidos pelas diferentes análises e discussão das diferentes estruturas e morfologias resultantes das diversas condições de processamento, as alterações observadas com o envelhecimento e finalmente chegou-se a conclusão do trabalho, interligando estrutura, propriedades e processamento. 


\section{OBJETIVOS}

Este trabalho tem como objetivos principais:

Estudar o efeito da radiação ionizante, produzida por feixe de elétrons, nas mudanças das propriedades mecânicas e térmicas das espumas de polietileno de baixa densidade reticulado.

Estudar o efeito da radiação ionizante no desempenho mecânico das espumas de LDPE após as mesmas sofrerem um processo de envelhecimento acelerado.

Determinar a melhor dose de radiação a que foi submetido o polietileno no processo de obtenção de espumas de LDPE, utilizado principalmente pela indústria calçadista no Brasil.

Avaliar a evolução das propriedades mecânicas com diferentes doses de radiação e o envelhecimento térmico acelerado.

Desenvolver um estudo detalhado sobre a morfologia e estrutura do polietileno reticulado por radiação e reticulado quimicamente com peróxido de dicumila. 


\section{REVISÃo BIBLIOGRÁFICA}

\subsection{Polietileno}

\subsubsection{Polietileno de baixa densidade (LDPE)}

O polietileno de baixa densidade é um termoplástico semicristalino, onde as regiões cristalinas têm uma estrutura esferulítica formada por lamelas que crescem radialmente. Esses esferulitos têm um diâmetro médio da ordem de $10 \mu \mathrm{m}$. A cristalinidade desse polímero situa-se geralmente em torno de 30 a $50 \%$. Isto se deve ao fato de que as ramificações das cadeias causam um impedimento estérico a uma maior aproximação intermolecular, diminuindo o empacotamento, reduzindo a possibilidade de maior ordenamento, responsável pela formação das regiões cristalinas. A estrutura cristalina típica do LDPE é a ortorrômbica com os seguintes parâmetros de rede: $a=0,742 \mathrm{~nm}, b=$ $0,494 \mathrm{~nm}$ e c $=0,255 \mathrm{~nm}$ (MARK, 1996). Os grupos $-\mathrm{CH}_{2-}$ formam longas cadeias ramificadas que contêm grupos terminais $-\mathrm{CH}_{3}$ (metilas) ou $-\mathrm{CH}=\mathrm{CH}_{2}$ (vinilas). $\mathrm{O} L D P E$ tem boa resistência química à maioria das solicitações, absorve pouca umidade, tem baixo custo e é de fácil processamento.

Convencionalmente o LDPE é manufaturado por processo contínuo (reator tubular) ou em batelada (autoclave), por meio de polimerização via radicais livres (poliadição). Em ambos os processos, etileno de alta pureza é polimerizado sob alta pressão (103,5 MPa a $276 \mathrm{MPa} ; 1,02 \times 10^{3} \mathrm{~atm}$ a $\left.2,72 \times 10^{3} \mathrm{~atm}\right)$ em temperaturas na faixa de $420-530 \mathrm{~K}\left(148^{\circ} \mathrm{C}-260^{\circ} \mathrm{C}\right)$ com um iniciador (MANO, 1999). A iniciação se dá pela cisão homolítica de oxigênio ou de um peróxido orgânico, como o peróxido de terc-butila representado na reação:

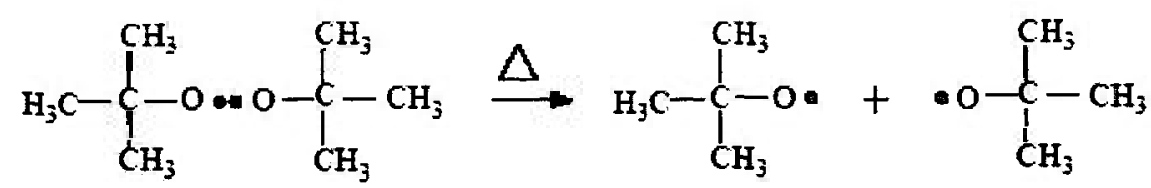


Uma vez formado, o radical iniciante ataca uma molécula de monômero:<smiles>CCCCCOC(C)(C)C</smiles><smiles>CCCOC(C)(C)C</smiles>

A propagação da reação se dá pela adição sucessiva de moléculas de etileno aos radicais formados na iniciação:

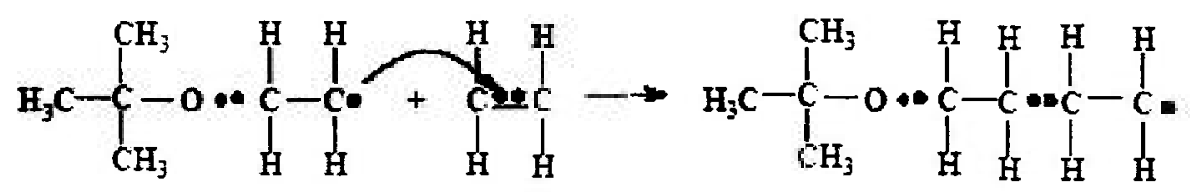

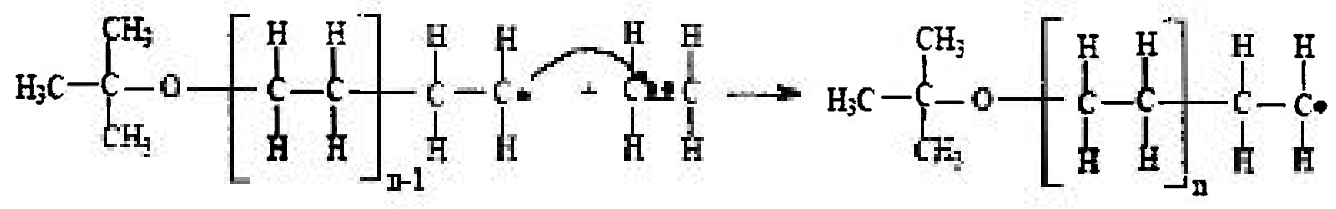


O término da reação se dá por combinação de dois radicais ou por desproporcionamento:

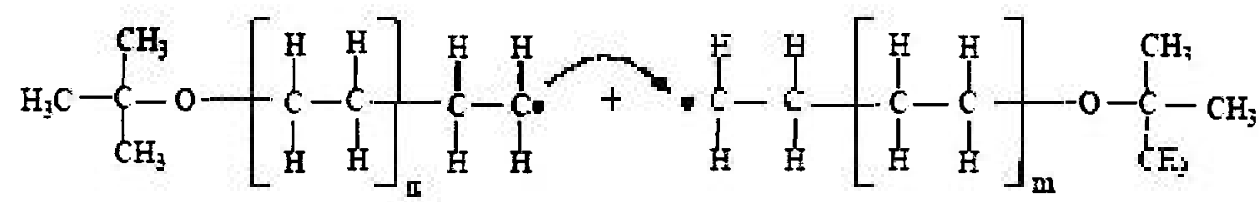

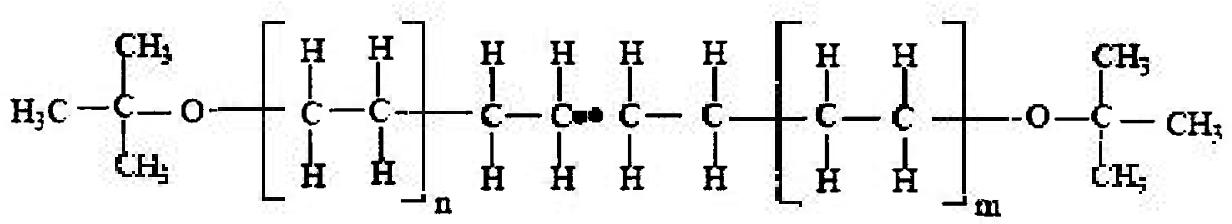

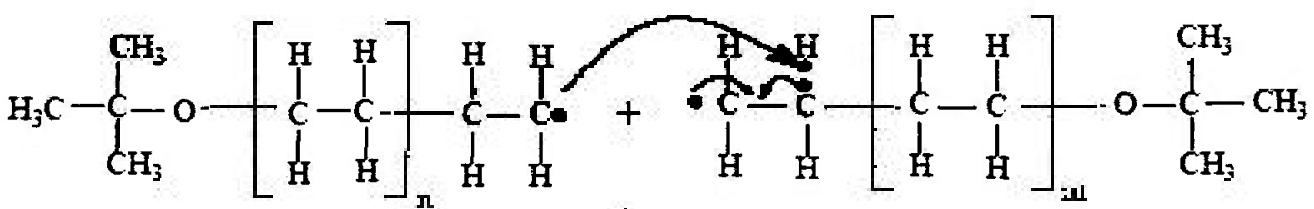

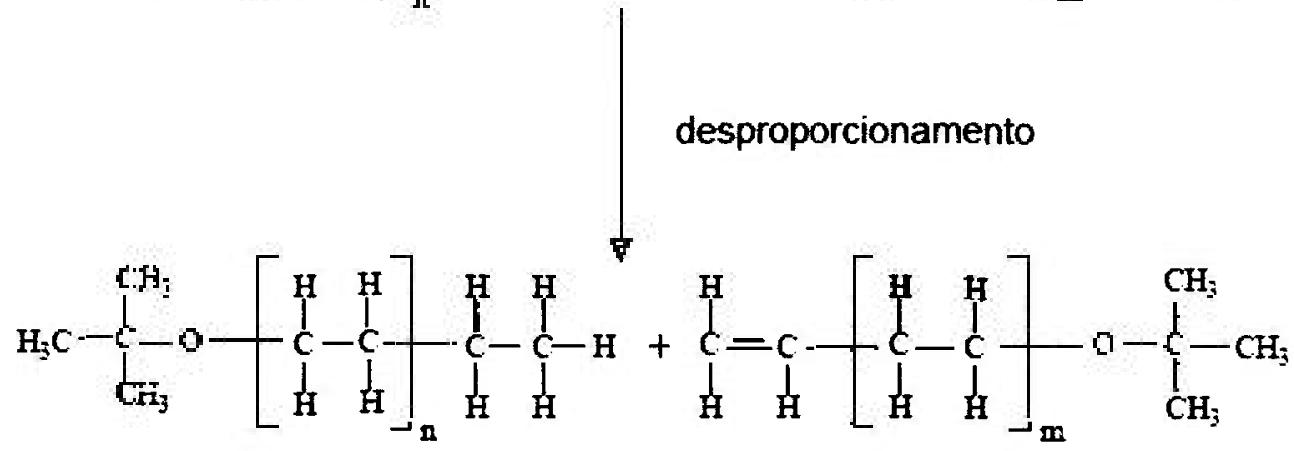


O polímero resultante tem uma estrutura ramificada devido às reações de transferência de cadeia inter e intramoleculares. Estas ramificações conferem ao LDPE propriedades de flexibilidade, podendo ser processado por extrusão, injeção, sopro, entre outros.

\subsubsection{Polietileno reticulado (XLPE)}

O polietileno reticulado (XLPE) exibe uma estrutura semicristalina similar à do LDPE, embora o tamanho dos esferulitos seja consideravelmente menor (CARON, 1996). Ele é geralmente obtido a partir do LDPE por reticulação (formação de ligações covalentes entre as macromoléculas). $O$ processo é feito principalmente por três métodos diferentes. No primeiro, viniltrietoxisilano ou viniltrimetoxisilano são "graftizados" na cadeia polimérica com o auxílio de pequenas quantidades de peróxido como iniciadores, seguido pela hidrólise do silano e reação de condensação do silanol (CELINA e GEORGE, 1995). As reações químicas correspondentes estão representadas a seguir: 


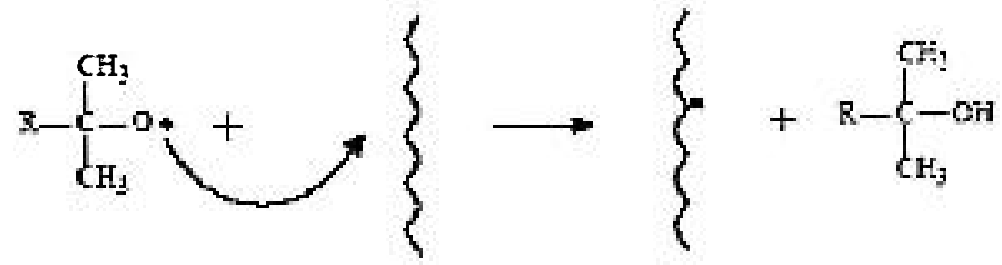

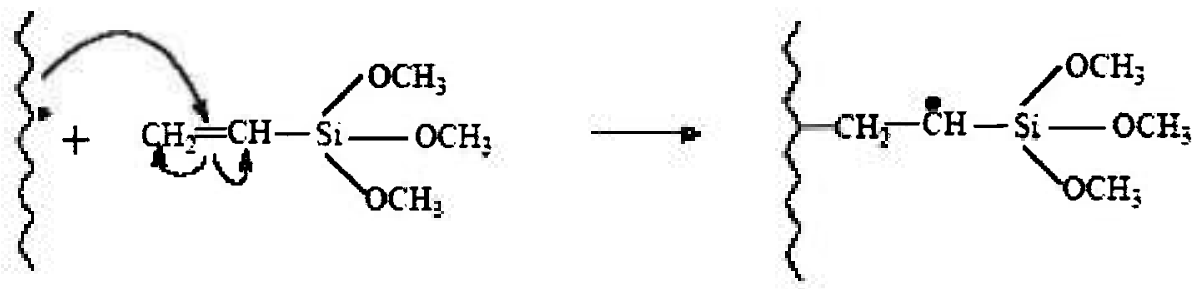

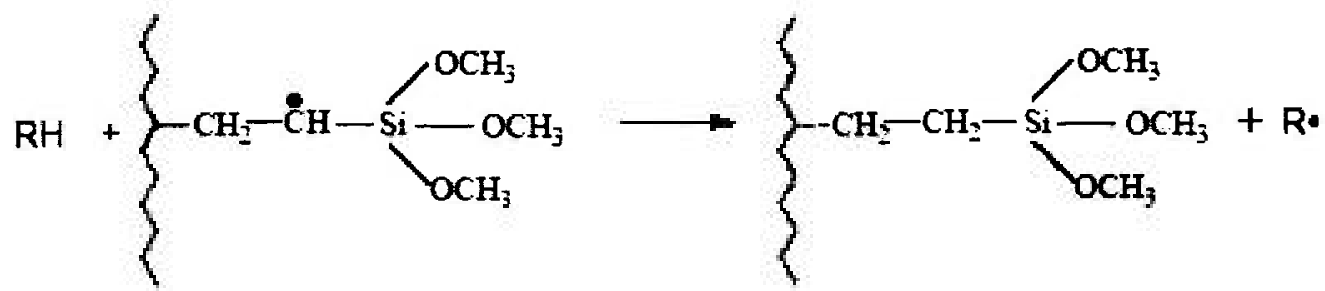<smiles>CCCCCC(CCCC)CC[Si](OC)(OC)OC</smiles>

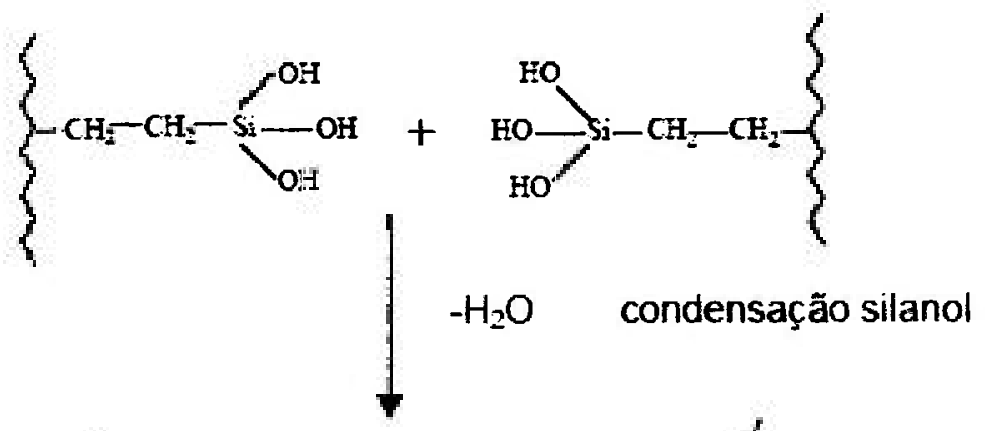<smiles>CCCCCC(CCCC)CC[Si](O)(O)O[Si](O)(O)CCC(CCCC)CCCCC</smiles> 
No segundo processo a radiação proveniente de feixe de elétrons ou radiação ultravioleta $(\mathrm{h} v)$ provoca a formação de radicais livres nas cadeias e estes se unindo promovem a ligação química entre cadeias.

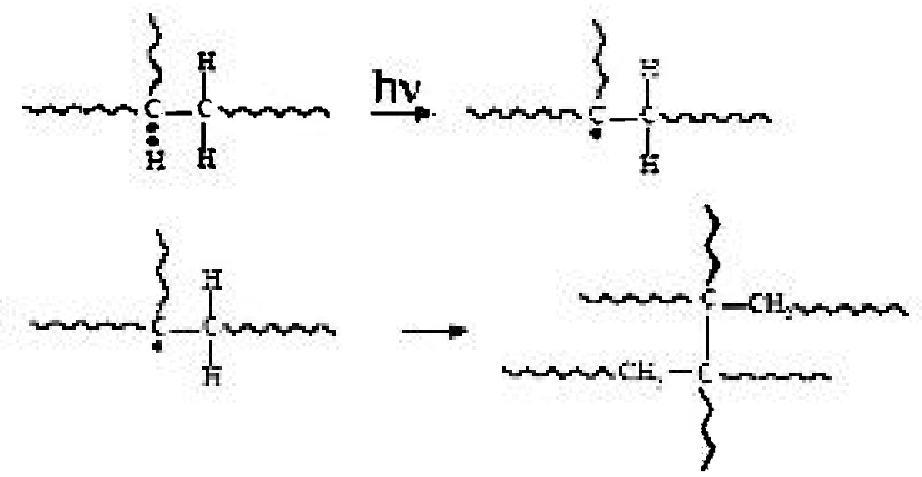

Neste processo o grau de reticulação é limitado pela profundidade de alcance do feixe de elétrons ou radiação ultravioleta ao longo da espessura do material. No processo com silano a permeação de água para o interior do polímero promovendo a hidrólise dos grupos alcoxi-silanos é a etapa determinante da velocidade do processo. Em ambos os casos o material final tem uma maior densidade de ligações cruzadas nas regiões mais próximas da superficie.

O terceiro método utiliza peróxidos orgânicos, sendo que o mais empregado é o peróxido de dicumila (DCP), sólido cristalino com energia de ativação para a decomposição de $37 \mathrm{kcal} / \mathrm{mol}$ (KIRCHER, 1987) e tempo de meia vida de 14 minutos a $150^{\circ} \mathrm{C}$ (Organic Peróxides, 1992). Sua fórmula molecular é representada por:<smiles>CC(C)(OOC(C)(C)c1ccccc1)c1ccccc1</smiles> 
A reação se dá pela decomposição térmica homolítica do peróxido, produzindo radicais livres. Esses radicais atacam a molécula do polimero formando um radical, pela abstração de hidrogênio. Em seguida ocorre a formação de ligações entre dois radicais, conforme ilustrado a continuação:
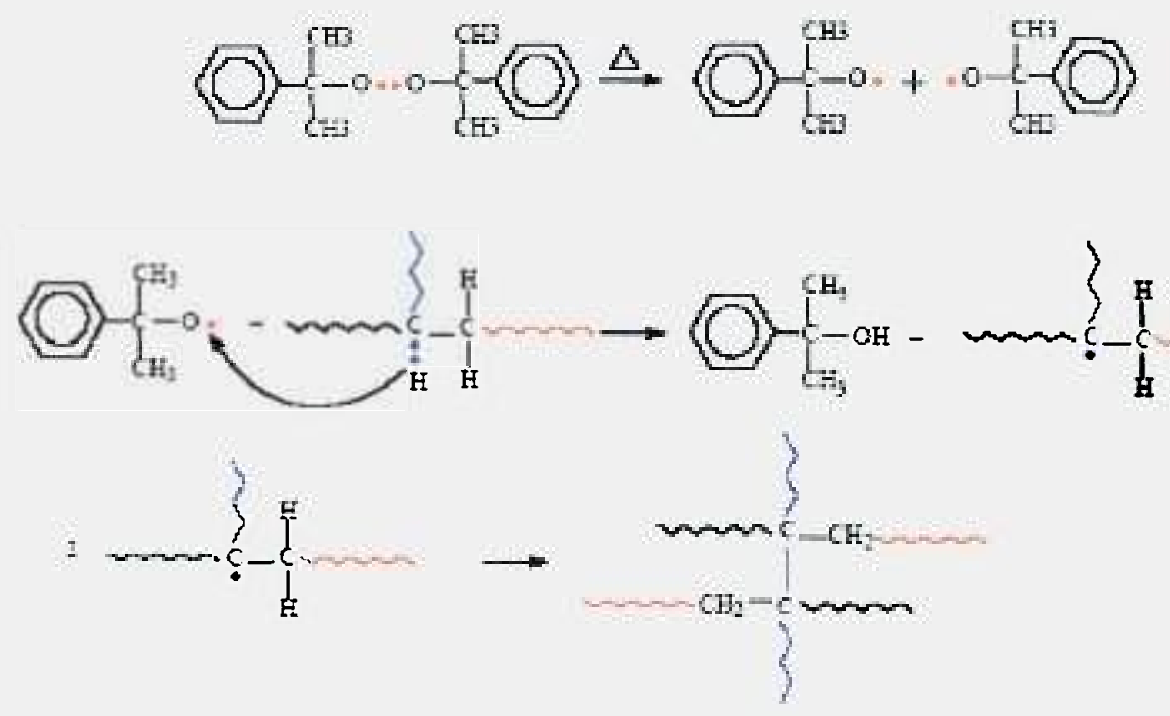

Geralmente incorpora-se em torno de $2 \%$ de peróxido ao polietileno, antes da extrusão, e submete-se a mistura a temperaturas superiores a $150^{\circ} \mathrm{C}$ e pressões acima de 14,80 atm (1,50 MPa) (ROSS, 1990). O produto final apresenta propriedades mecânicas, fisicas e químicas superiores ao LDPE.

O uso de peróxidos permite uma distribuição mais uniforme das interconexões das cadeias por todo o volume do material. Por outro lado, os subprodutos gerados durante a decomposição do peróxido tais como acetofenona, $\alpha$-metil estireno e álcool cumílico, podem exercer um efeito deletério no desempenho mecânico do material.

\subsection{Envelhecimento artificial acelerado de polímeros}

Devido à grande utilização de polímeros nas mais diversas aplicações ao ar livre, surgiu a necessidade de estudar sua resistência às intempéries, não somente por aspectos estéticos, como descoloração ou perda de brilho, mas também por mudanças nas suas propriedades. $\mathrm{O}$ estudo do envelhecimento é de grande importância para o desenvolvimento de materiais mais resistentes e de aditivos que forneçam maior vida útil aos polímeros. Com esse intuito foram criados vários métodos de envelhecimento ao ar 
livre e também equipamentos de envelhecimento acelerado em laboratório, sendo estes últimos preferencialmente utilizados quando se deseja um diagnóstico do material em um tempo mais curto de exposição.

\subsection{Espumas de polietileno}

As espumas obtidas a partir de polietileno mantêm muitas das propriedades das resinas do polímero.

Uma patente para preparação de polietileno expandido (PE) foi apresentada por Johnston da Du Pont em 1942 utilizando nitrogênio como agente expansor. Porém, este processo não teve utilização comercial. Dentre as patentes emitidas para a obtenção de PE expandido, a mais adiantada foi atribuída a Hamilton em 1945 utilizando dióxido de carbono como agente expansor (FRISCH, 1981). Mas estes métodos não alcançaram sucesso comercial significante. Muitas outras patentes têm sido apresentadas para a expansão de poliolefinas, principalmente o PE, pela incorporação ou dissolução de um gás na resina fundida sob alta pressão, ou reduzindo a pressão com resfriamento simultâneo. Rubens e Griffin (1962) prepararam espumas de polietileno não-reticulado, utilizando 1,2diclorotetrafluoroetano (CFC 114) como agente expansor. Para obter-se espumas de poliolefinas de baixa densidade a partir da decomposição de um agente químico expansor (CBA), é necessário reticular o polímero. A reticulação não somente estabiliza as bolhas durante a expansão, como também aumenta a resistência do produto celular ao colapso térmico (KLEMPNER e FRISCH, 1991).

O aumento da resistência ao colapso térmico, é necessário para algumas aplicações, tais como, a utilização como isolamento térmico, vedação e amortecimento.

Existem dois métodos para reticulação do polietileno, usado para obtenção de espumas. No primeiro método, ligações intermoleculares são formadas pela decomposição de agentes químicos, como os peróxidos. Nesse método, a decomposição do agente expansor ocorre simultaneamente com a expansão. No segundo método, uma estrutura tridimensional é formada pela irradiação da amostra, porém, a reticulação e a expansão ocorrem em etapas separadas.

O fluxograma do processo de obtenção de espumas de polietileno reticulado por radiação é mostrado na FIG. 1. O processo é feito em quatro etapas: mistura do polímero com o agente expansor, extrusão da mistura para formar placas de espessura desejada, reticulação das placas pelo processo de irradiação, e expansão das placas em um forno. 


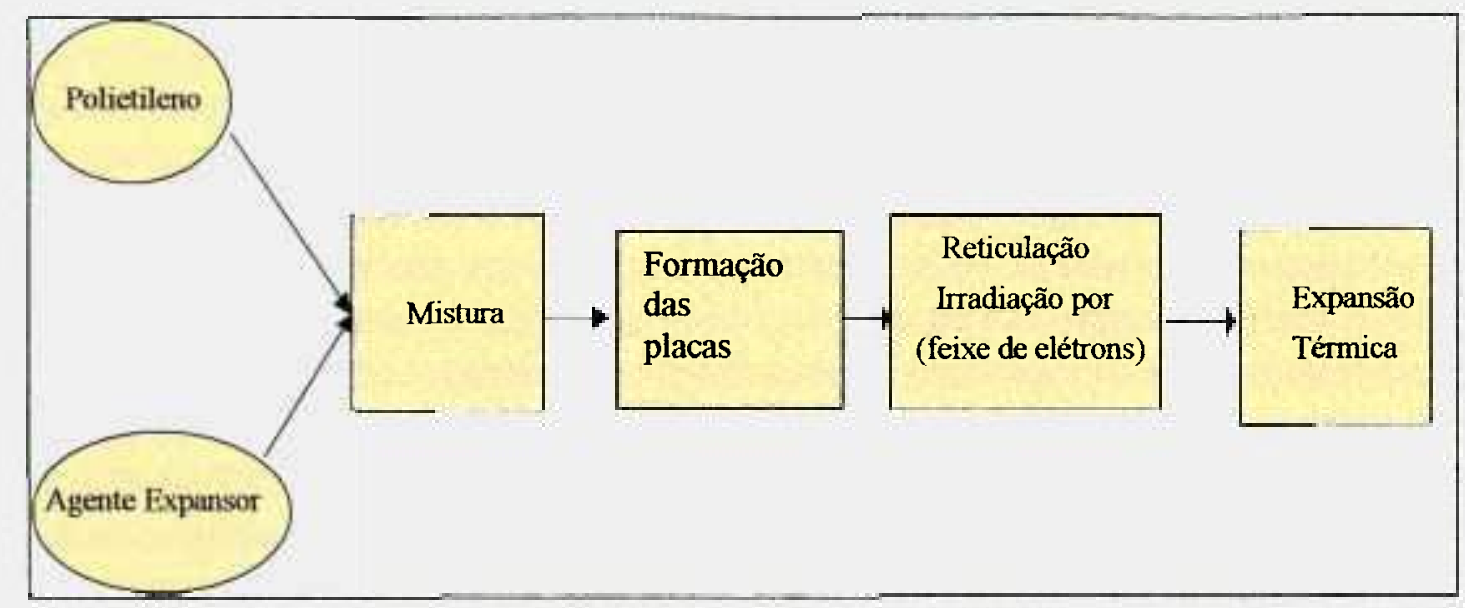

FIGURA 1 - Diagrama do processo de formação de espumas de polietileno reticulado por feixe de elétrons

\subsubsection{Princípios fundamentais de formação de espuma}

Existem três etapas fundamentais envolvidos na formação de espumas: formação das bolhas, crescimento das bolhas, e estabilização das bolhas. Para obter uma estrutura celular desejável de um produto expandido ou espuma, o entendimento do mecanismo do processo de expansão é essencial.

\subsubsection{Formação da bolha}

A nucleação de várias bolhas a partir de uma solução supersaturada de gás em um polímero é o caminho para alcançar uma estrutura celular uniforme. Na presença de agentes nucleantes, a formação da bolha pode ocorrer muito rapidamente e diminuir a concentração do gás. Em outras palavras, uma nucleação heterogênea, fornece abundância de sítios de nucleação no fluido supersaturado, o qual é muito mais efetivo do que a nucleação homogênea facilitando a formação de bolhas e produzindo uma estrutura celular uniforme. Hansen e Martin (1965) relataram um aumento de dez vezes de partículas nucleadoras, e uma diminuição de cinqüenta vezes no volume de cada bolha, aproximadamente o mesmo nível de supersaturação.

\subsubsection{Crescimento da bolha}

Desde o trabalho pioneiro de Rayleigh em 1917 (ZHANG, 2001), a relação fixa de crescimento/colapso da bolha esférica tem sido objeto de considerável interesse para muitos pesquisadores. Desprezando a resistência hidrodinâmica do líquido para com o crescimento da bolha, Epstein e Plesset (1950) desenvolveram uma teoria de crescimento 
difusão-controlada (e colapso) da fase estacionária da bolha de gás baseado em uma média Newtoniana. Eles obtiveram uma solução aproximada para o crescimento da bolha como:

$$
R(t)=K^{\prime} t^{1 / 2}
$$

em que:

$\mathrm{R}(\mathrm{t})$ é o raio da bolha,

t é o tempo total de expansão para formação da espuma,

K'é a constante.

Gent e Tompkins (1969) relataram que a equação (1) descreve adequadamente a cinética de crescimento da bolha numa média puramente elástica. Stewart (1970) também relatou que os seus resultados experimentais de crescimento de bolhas em elastômeros termoplásticos estavam de acordo com o previsto na equação (1).

Devido a algumas suposições usadas na derivada da eq. (1), Han e Villamizar (ZHANG, 2001), observaram desvios entre seus resultados experimentais e a teoria de Epstein-Plesset.

\subsubsection{Estabilidade da bolha}

As bolhas já formadas podem continuar a expandir, combinando, colapso e ruptura. Existem principalmente três razões para que isto ocorra:

a) Estas bolhas são termodinamicamente instáveis. A formação de bolhas em um líquido requer um aumento da energia livre do sistema, como dado na equação (2). Assim, um aumento de A aumenta $\Delta \mathrm{F}$ o qual é termodinamicamente desfavorável.

$$
\Delta \mathrm{F}=\sigma \mathrm{A}
$$

em que:

$\Delta \mathbf{F}$ é a alteração da energia livre do sistema, $\sigma$ é a tensão de superfície do líquido, A é a área interfacial total. 
b) A pressão do gás em uma pequena bolha é maior do que em uma bolha grande, como visto na equação (3) de Laplace. O gás tenderá a se difundir a partir de uma bolha menor.

$$
\Delta \mathrm{P}=\mathrm{P}_{\mathrm{s}}-\mathrm{P}_{\mathrm{b}}=2 \sigma\left[\left(\mathrm{R}_{\mathrm{s}}-\mathrm{R}_{\mathrm{b}}\right) /\left(\mathrm{R}_{\mathrm{s}} \cdot \mathrm{R}_{\mathrm{b}}\right)\right]
$$

em que:

$\Delta P$ é a diferença de pressão entre as duas bolhas tendo raios de $\mathbf{R}_{\mathbf{s}} \mathbf{e} \mathbf{R}_{\mathrm{b}}$, $\sigma$ é a tensão de superfície do líquido.

c) A gravidade favorece o colapso de espumas líquidas. As paredes da bolha podem ser diluídas pela drenagem, devido à gravidade e também pela ação da capilaridade. De acordo com Devries, 1958, este efeito pode conduzir a uma drenagem excessiva das paredes ocorrendo ruptura (ZHANG, 2001).

Quando polímeros fundidos contêm uma grande quantidade de bolhas, o processo de sua solidificação é a troca do sistema gás-líquido para o sistema gás-sólido. Em outras palavras, é o processo no qual a viscosidade do líquido aumenta gradualmente, perdendo finalmente a sua capacidade de fluir (solidifica).

Consideram-se os seguintes fatores que afetam a solidificação:

- Transferência de calor,

- Quantidade de gás liberado do fundido,

- Decomposição do agente expansor.

\subsection{Radiação Ionizante}

As radiações ionizante podem ser classificadas em eletromagnéticas e partículas com cargas elétricas como os elétrons. Estas radiações são emitidas por elementos com núcleos atômicos instáveis ou podem ser produzidas pelos equipamentos denominados fontes intensas de radiações como os aceleradores de elétrons (SPINKS, 1990). A continuação será dada ênfase aos aceleradores de elétrons que foi utilizado na irradiação das amostras neste trabalho.

\subsubsection{Aceleradores de elétrons}

A potência máxima do feixe de elétrons está diretamente relacionada com a voltagem de aceleração e a corrente de elétrons. 
O acelerador de elétrons Dynamitron JOB-188, do Centro de Tecnologia das Radiações (CTR) do IPEN é composto dos seguintes itens:

-Sistema de varredura;

-Gerador de alta tensão

-Sistema de vácuó;

-Bandeja com suporte para as amostras a serem irradiadas;

-Esteira transportadora;

-Variação de energia: de 0,5 a 1,50 MeV;

-Corrente: até $25 \mathrm{~mA}$.

No acelerador, os elétrons são produzidos em um cátodo aquecido mantido em uma região de potencial mais elevado. Estes elétrons são então acelerados por uma diferença de potencial aplicada entre o cátodo e o ânodo.

Com a aceleração, os elétrons adquirem energia suficiente para atravessar a janela de saída, constituída de uma folha de titânio (espessura entre 20 e $40 \mu \mathrm{m}$ ), que apresenta resistência mecânica suficiente para suportar a pressão atmosférica do exterior.

O acelerador de elétrons, o sistema de varredura e o tubo de aceleração são mantidos em alto vácuo, permitindo a aceleração dos elétrons para controlar seu foco e varredura.

Na FIG. 2 é mostrado o sistema de irradiação do Acelerador de Elétrons Dynamitron JOB-188, do Centro de Tecnologia das Radiações (CTR) do Instituto de Pesquisas Energéticas e Nucleares (IPEN), o qual foi utilizado no presente trabalho. 


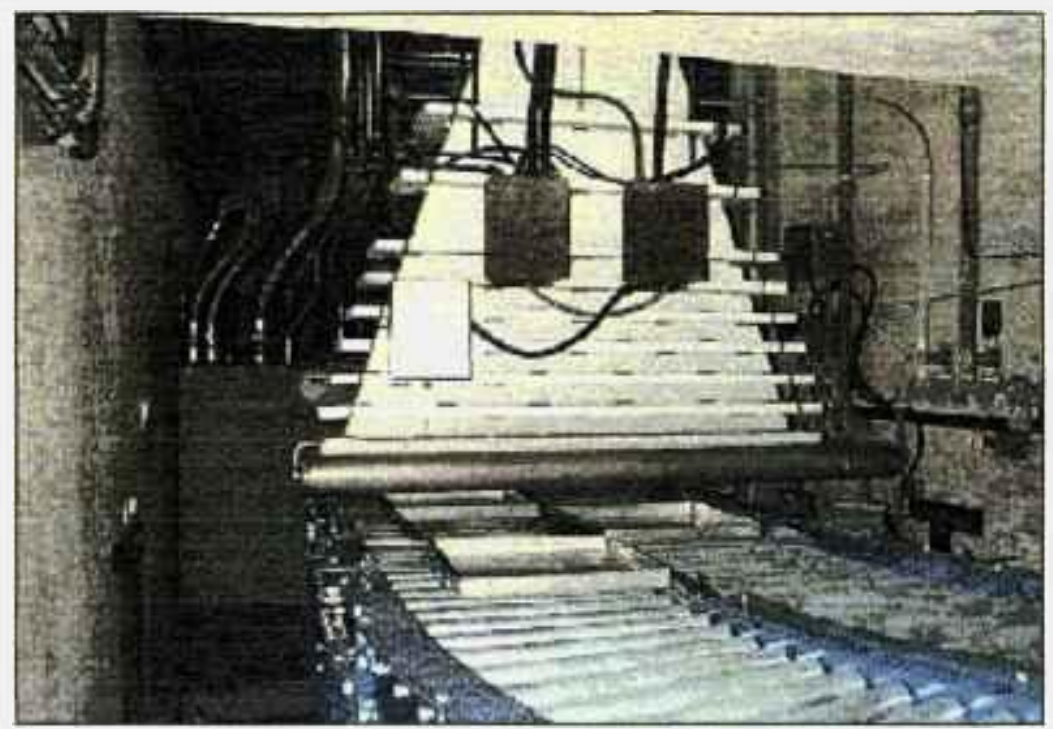

FIGURA 2 - Sistema de varredura do feixe do acelerador de elétrons do Centro de Tecnologia das Radiações do IPEN

\subsubsection{Efeito da radiação ionizante em polímeros}

O efeito da radiação ionizante em polímeros possui principalmente, duas aplicações economicamente viáveis: a modificação de polímeros por meio de processos de reticulação e degradação, e a esterilização de produtos farmacêuticos entre outros.

Dois tipos principais de radiação podem ser usados no processo de irradiação de polímeros: radiação gama proveniente de radioisótopos e elétrons proveniente de aceleradores de elétrons. A utilização da radiação ionizante em materiais poliméricos vem crescendo cada vez mais devido às grandes possibilidades de modificação de suas propriedades sem a formação de resíduos. A interação da radiação ionizante com materiais poliméricos transfere energia aos materiais, provocando principalmente a excitação e a ionização das moléculas, gerando reações químicas que podem provocar modificações permanentes na estrutura físico-quimica dos polímeros (CHARLESBY, 1952). Os dois principais efeitos da interação da radiação ionizante com polímeros são:

a) Processo aleatório de cisão da cadeia principal (degradação), com redução da massa molar do polímero.

Todo processo que conduz a uma mudança drástica de propriedades consideradas importantes para uma aplicação específica do polímero pode ser incluída no termo degradação. Na maioria dos casos as mudanças são manifestadas por meio das reações de cisão nas cadeias das macromoléculas, mas também podem ser causadas pela quantidade excessiva de reticulação. 
Devido à alta energia da radiação ionizante tal evento é comum e aleatório em polimeros e nem sempre predominante (CLOUGH, 1991). A predominância depende da dose, taxa de dose e estrutura química do polímero. A cisão promove a redução da massa molar do polímero, da viscosidade, da resistência mecânica do material e um rearranjo dos grupos próximos ao ponto de cisão (GRUENWALD, 1993).

b) reticulação, que também é aleatório, com aumento da massa molar e modificação nas propriedades do polímero.

A reticulação é a formação de ligações químicas entre as cadeias moleculares formando estruturas tridimensionais interligadas no polímero irradiado (O'DONNEL e SANGSTER, 1970).

Os efeitos da reticulação são manifestados no aumento da massa molar, da viscosidade e na diminuição da solubilidade do polímero irradiado. Vários são os parâmetros que influenciam no processo de reticulação, tais como: dose, taxa de dose, concentração, entre outros. No entanto, deve-se levar em consideração também, o tipo e tamanho das cadeias, e a morfologia do polímero (CHAPIRO e LEGRIS, 1986). A reticulação aumenta a resistência mecânica e térmica dos polímeros com o aumento de redes tridimensionais dos mesmos.

Ambos os processos, cisão e reticulação, são produzidos simultaneamente durante a irradiação, e a predominância de um deles sobre o outro depende da estrutura química do polímero e das condições de irradiação (CHARLESBY, 1952).

As reações de reticulação são as seguintes:

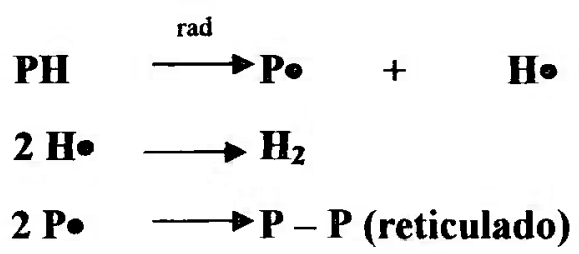

A absorção da energia proveniente da radiação ionizante inicia uma seqüência de inúmeros eventos. Esses eventos são complexos e podem ser divididos nos seguintes estágios (O'DONNEL e SANGSTER, 1970):

- Estágio físico $\left(10^{-18} \mathrm{~s}\right.$ a $\left.10^{-15} \mathrm{~s}\right)$ : a energia transferida provoca excitações moleculares e ionização. As espécies formadas são muito instáveis sofrendo reações secundárias tanto espontaneamente como por colisão com moléculas vizinhas.

- Estágio físico-químico $\left(10^{-14} \mathrm{~s}\right.$ a $\left.10^{-11} \mathrm{~s}\right)$ : formação de espécies secundárias reativas e radicais livres. 
- Estágio químico $\left(10^{-10} \mathrm{~s}\right.$ em diante): o sistema restabelece o equilíbrio térmico. As espécies reativas continuam a reagir entre si e com outras espécies vizinhas

Os tipos de radiações ionizante mais empregados em processos industriais são a radiação gama, proveniente de fontes radioisotópica, e feixe de elétrons de alta energia proveniente de aceleradores (BOLT e CARROL, 1991)

Uma resina de LDPE pode ser reticulada por irradiação, como apresentado por Charlesby (1952), Rado (1993) e Chodak (1995), ou por peróxido, como fez Ivett (PARK, 1991).

Outros estudos sobre os efeitos da radiação em polietileno para obtenção de espumas foram realizados utilizando a radiação gama e feixe de elétrons:

Adem e colaboradores (1995) estudaram a reticulação do polietileno fabricado no México pela PEMEX, com o azodicarbonamida (ADCA) como agente expansor, utilizando radiação gama e feixe de elétrons e comparando as suas propriedades. O estudo foi realizado com radiação gama, utilizando amostras de polietileno de baixa densidade, contendo 5\% de ADCA como agente expansor, selado à vácuo e irradiado a diferentes doses a uma taxa de dose de $5,1 \mathrm{kGy} / \mathrm{h}$. Com elétrons, as amostras foram colocadas em sacos selados de polietileno e irradiadas a uma taxa de dose de $720 \mathrm{kGy} / \mathrm{h}$ e doses de $50 \mathrm{a}$ 1000 kGy. Após a irradiação, foi determinado o grau de reticulação das amostras e confirmou-se que as amostras reticuladas por raios gama precisaram de doses menores do que as reticuladas por feixe de elétrons.

Cardoso e colaboradores (1998) estudaram a obtenção de espumas com diferentes quantidades do agente expansor, ADCA, reticuladas por radiação, utilizando feixe de elétrons. Foram estudadas as propriedades mecânicas e o tempo de expansão de espumas com 5, 10, 12 e 15\% de agente expansor.

Adem e colaboradores (1998) em outro trabalho, estudaram a reticulação de polietileno reciclado, utilizando radiação gama e elétron para comparar os efeitos dos dois tipos de radiação sobre as propriedades mecânicas, térmicas e químicas do polietileno virgem e reciclado

Kim e Kim (2002) estudaram os efeitos nas propriedades de espumas de blendas formadas por polietileno de baixa densidade (LDPE) e acetato de vinil etileno (EVA), LDPE-EVA não reticulados. Utilizaram feixe de elétrons. As propriedades estudadas foram: tensão, deformação, compressão, dureza e estabilidade dimensional 
Nesse trabalho, foi concluído que a irradiação é um método efetivo para reticulação de espumas não reticuladas formadas por blendas.

Danaei e Sheikhy (2005) estudaram o efeito da radiação gama sobre espumas já reticuladas com diferentes porcentagens de peróxido de dicumila (DCP), tendo ADCA como agente expansor, também usaram um agente promotor de reticulação, o monômero multifuncional trimetilolpropano trimetil trimetacrilato (TMPTA). As amostras foram irradiadas a uma taxa de dose de $2,57 \mathrm{kGy} / \mathrm{h}$ e doses de 10 a $80 \mathrm{kGy}$ a temperatura ambiente. Foram estudados o tempo e a temperatura do processo de expansão, e a condutividade térmica das espumas.

Confirmou-se que agentes promotores de reticulação (TMPTA) levam a uma maior reticulação no polietileno, especialmente a baixas doses. Este efeito também depende do tipo e concentração do agente promotor de reticulação.

Yang e Lee (2003) avaliaram a estabilidade dimensional de espumas de blendas de LDPE e copolímero etileno/estireno. As alterações causadas pelo envelhecimento foram investigadas.

Liu e colaboradores (2004) fizeram um estudo experimental de espumas reticuladas pelo processo de irradiação, utilizando feixe de elétrons. As espumas foram obtidas a partir de blendas de polietileno reciclado (RPE) com polietileno virgem (PE), utilizando o ADCA como agente expansor. A morfologia das células e as propriedades mecânicas de várias espumas de RPE/PE foram estudadas. Nesse trabalho, foi concluído que boas propriedades são obtidas quando as espumas contêm 5\% de RPE na blenda. O grau de reticulação e expansão foram fortemente afetados pela porcentagem de polietileno reciclado.

Com base na pesquisa bibliográfica realizada pode-se dizer que as propriedades das espumas dependem da densidade e da estrutura celular. A densidade é influenciada pela estrutura do polímero, pelo agente reticulante e a concentração do agente expansor.

As espumas de polietileno reticuladas pelo processo de irradiação com feixe de elétrons, apresentam superficie lisa e homogênea, quando comparadas com as reticuladas pelo processo químico, utilizando peróxido como agente reticulante o que foi comparado no presente estudo.

O estudo das espumas de polietileno reticuladas pelo processo de irradiação se fez necessário devido ao seu grande consumo e por ser um processo simples e com alta produtividade e pelo interesse do setor de calçados aqui no Brasil. 


\section{MATERIAIS E MÉTODOS}

Este trabalho foi realizado utilizando polietileno de baixa densidade (LDPE), fornecido pela Empresa Trocellen, com densidade de $0,946 \mathrm{~g} / \mathrm{cm}^{3}$, contendo aproximadamente $5 \%$ de agente expansor azodicarbonamida (ADCA).

\subsection{Irradiação}

As irradiações das amostras de polietileno em placas de dimensões de $200 \mathrm{x}$ $200 \times 1,91 \mathrm{~mm}$ foram realizadas no acelerador de elétrons tipo JOB 188 de energia de 0,5 a 1,5 MeV e corrente de 0,1 a $25 \mathrm{~mA}$, do Centro de Tecnologia das Radiações (CTR/IPEN), com doses de radiação de 10 a $100 \mathrm{kGy}$ e taxa de dose de $22,39 \mathrm{kGy} / \mathrm{s}$.

\subsection{Teor de gel ou grau de reticulação}

O grau de reticulação, que corresponde ao percentual em peso de material reticulado de polietileno, afeta as propriedades mecânicas e térmicas do material polimérico. Trata-se de um ensaio importante para caracterização inicial do polímero, pois certos limites mínimos de reticulação devem ser observados para garantir características térmicas e mecânicas do material. $O$ teor de gel de cada amostra de espuma foi determinado pelo método descrito pela norma ASTM D 2765-95.

As amostras picadas foram pesadas em porções de $0,3 \mathrm{~g}$ e colocadas em balão de fundo redondo de $500 \mathrm{~mL}$ usando como solvente $400 \mathrm{~mL}$ de Xilol. Este balão foi conectado a um condensador e as amostras permaneceram sob refluxo a $130^{\circ} \mathrm{C}$ durante 24 horas. Transcorrido este tempo, o conteúdo do balão foi pesado após secagem até peso constante (cerca de $8 \mathrm{~h}$ ) a $70^{\circ} \mathrm{C}$. O teor de gel foi calculado a partir das massas final e inicial, utilizando a equação (4):

$$
\% \text { de reticulação }=100-[(\mathrm{B}-\mathrm{C}) / \mathrm{A}] \times 100
$$

em que:

$A=$ massa inicial da amostra,

$B=$ massa inicial da amostra junto com o suporte da amostra,

$\mathrm{C}=$ massa final da amostra junto com o suporte. 


\subsection{Expansão térmica}

As placas de polietileno reticulado foram cortadas com dimensões de $40 \mathrm{~cm} \mathrm{x}$ $40 \mathrm{~cm}$ e colocadas verticalmente em um forno com circulação forçada de ar (FIG. 3 e 4), para obtenção de espumas. A temperatura utilizada foi de $229^{\circ} \mathrm{C}$, produzindo a decomposição térmica do azodicarbonamida, gerando os gases $\mathrm{N}_{2}, \mathrm{CO}$ e $\mathrm{CO}_{2}$. O tempo de expansão foi entre 4 e 6 minutos em função da dose de radiação.

$$
\mathrm{H}_{2} \mathrm{~N}-\mathrm{C}(\mathrm{O})-\mathrm{N}=\mathrm{N}-\mathrm{C}(\mathrm{O})-\mathrm{NH}_{2} \longrightarrow \mathrm{N}_{2}+\mathrm{CO}+\mathrm{CO}_{2}+\text { sólidos }
$$

É muito importante selecionar a temperatura de cada etapa, que depende do ponto de fusão do polímero $\left(\mathrm{T}_{\mathrm{m}}\right)$ e da temperatura de decomposição do agente expansor $\left(T_{d}\right)$. A temperatura de expansão $\left(T_{f}\right)$, obviamente, está acima da $T_{d}$.

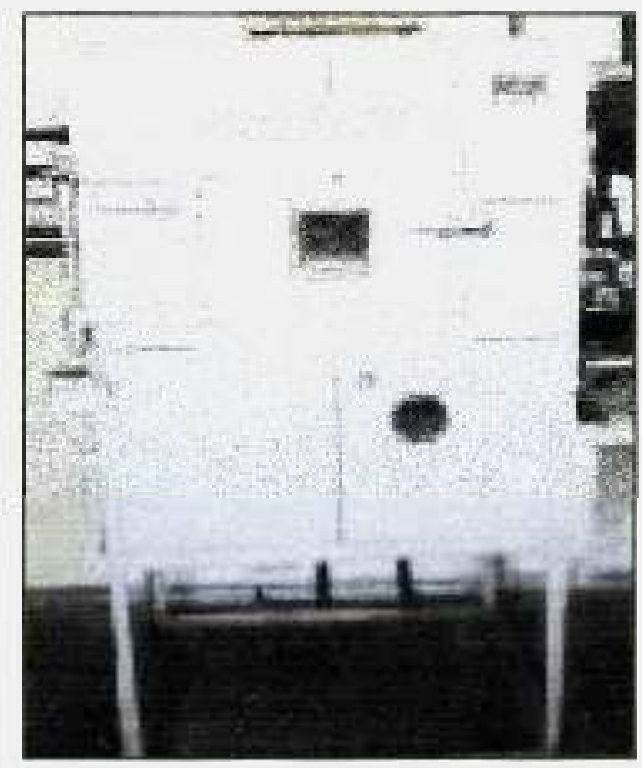

FIGURA 3 - Forno com circulação de ar

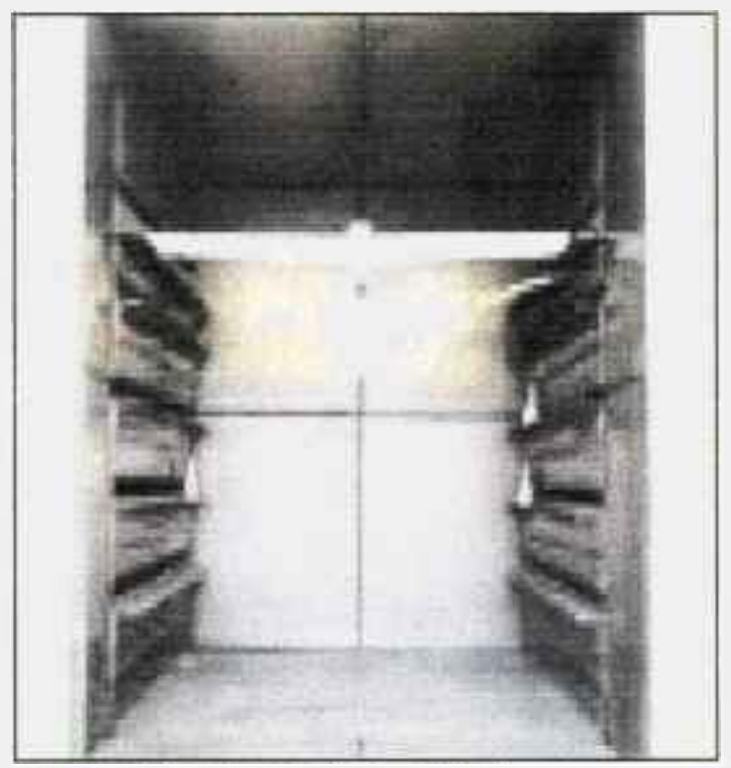

FIGURA 4 - Expansão do polietileno

\subsection{Termogravimetria (TGA)}

Este ensaio visa acompanhar por meio de uma termobalança, variações de massa sofrida pela amostra em função da temperatura, quando esta é submetida a uma programação de temperatura. Faixas de temperatura de decomposição e concentração do agente expansor na amostra também podem ser medidas.

O polímero submetido a um programa de aquecimento, sofre degradação com evolução de produtos voláteis. Por meio de curvas de TGA consegue-se acompanhar o ganho ou a perda de massa em função da temperatura. Os ensaios de termogravimetria em 
atmosfera de nitrogênio foram realizados no equipamento TG/SDTA Mettler Toledo, Modelo 822, do Laboratório de Polímeros do Centro de Química e Meio Ambiente (CQMA) do IPEN. Foram utilizadas amostras de massa entre 3 e $6 \mathrm{mg}$, em cadinho de platina, faixa de temperatura de 30 a $600^{\circ} \mathrm{C}$ e razão de aquecimento de $20^{\circ} \mathrm{C} / \mathrm{min}$., tendo como objetivo verificar a temperatura de decomposição do polietileno irradiado e nãoirradiado.

\subsection{Densidade das espumas de LDPE}

A densidade das espumas foi determinada de acordo com a norma ASTM D3575-77, utilizando-se cinco amostras e determinando-se a média.

\subsection{Ensaio de envelhecimento e verificação da estabilidade térmica}

As propriedades mecânicas das espumas podem sofrer variações com o envelhecimento. As amostras de espumas com densidade de $0,099 \mathrm{~g} / \mathrm{cm}^{3}$, reticuladas por feixe de elétrons e por peróxido, foram cortadas com dimensões definidas e colocadas em estufa com circulação de ar, à temperatura de $70^{\circ} \mathrm{C}$, durante 24 horas. Após a exposição ao calor, as mesmas foram resfriadas por um periodo de 2 horas e foram determinadas as suas dimensões finais, segundo a norma ASTM D 3575-77.

Também foram avaliadas as suas propriedades mecânicas de tensãodeformação e compressão.

\subsection{Ensaios mecânicos}

Os ensaios mecânicos têm o objetivo de avaliar o efeito da radiação sobre as propriedades mecânicas das espumas antes e após a exposição das amostras em um forno para verificar a sua degradação térmica.

\subsubsection{Resistência à tração}

Esta é uma das mais importantes indicações de resistência em um material. A resistência à tração, de um modo geral, é a medida da capacidade de um material resistir à forças que tendem a puxar e separá-lo e determinar o quanto ele estende antes da ruptura.

Foram realizados ensaios de tração à ruptura e alongamento, com uma velocidade de $50 \mathrm{~mm} / \mathrm{min}$. Este ensaio teve como finalidade determinar a resistência à tração do nosso material. As tensões, no ensaio de resistência à tração, foram realizados utilizando a seguinte relação: 


$$
\sigma=\mathbf{F} / \mathbf{A}_{0}
$$

em que:

$\sigma=$ tensão,

$F=$ força nos limites pré-determinados,

$\mathrm{A}_{0}=$ área transversal inicial do corpo-de-prova

As deformações foram medidas nos pontos selecionados e por meio delas todas as propriedades correlacionadas. As deformações foram calculadas utilizando a seguinte relação:

$$
\varepsilon=\Delta \mathrm{L} / \mathrm{L}_{0}
$$

em que:

$\varepsilon=$ deformação,

$\Delta \mathrm{L}=$ variação de comprimento,

$\mathrm{L}_{0}=$ comprimento inicial.

Os resultados foram obtidos a partir de cinco corpos-de-prova para as determinações em cada dose na forma de gravatas, mostrados na FIG. 5 para cada amostra com as dimensões segundo a norma ASTM D 638-03. Estas gravatas foram confeccionadas por estampagem. 


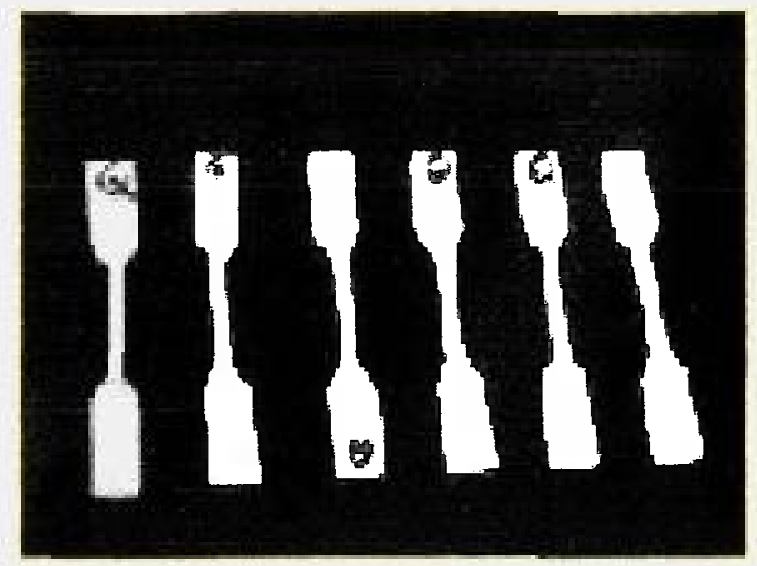

FIGURA 5 - Corpos-de-prova de espumas de LDPE para ensaios de tração

\subsubsection{Resistência à Compressão}

Foram realizados também testes de compressão de acordo com a norma ASTM D 3575-77, usando o método B, antes e após exposição das amostras em um forno para verificar a degradação térmica das espumas. Os testes de tração e compressão foram realizados na máquina de ensaios mecânicos Instron, modelo 5567, mostrada nas FIG. 6 e 7.

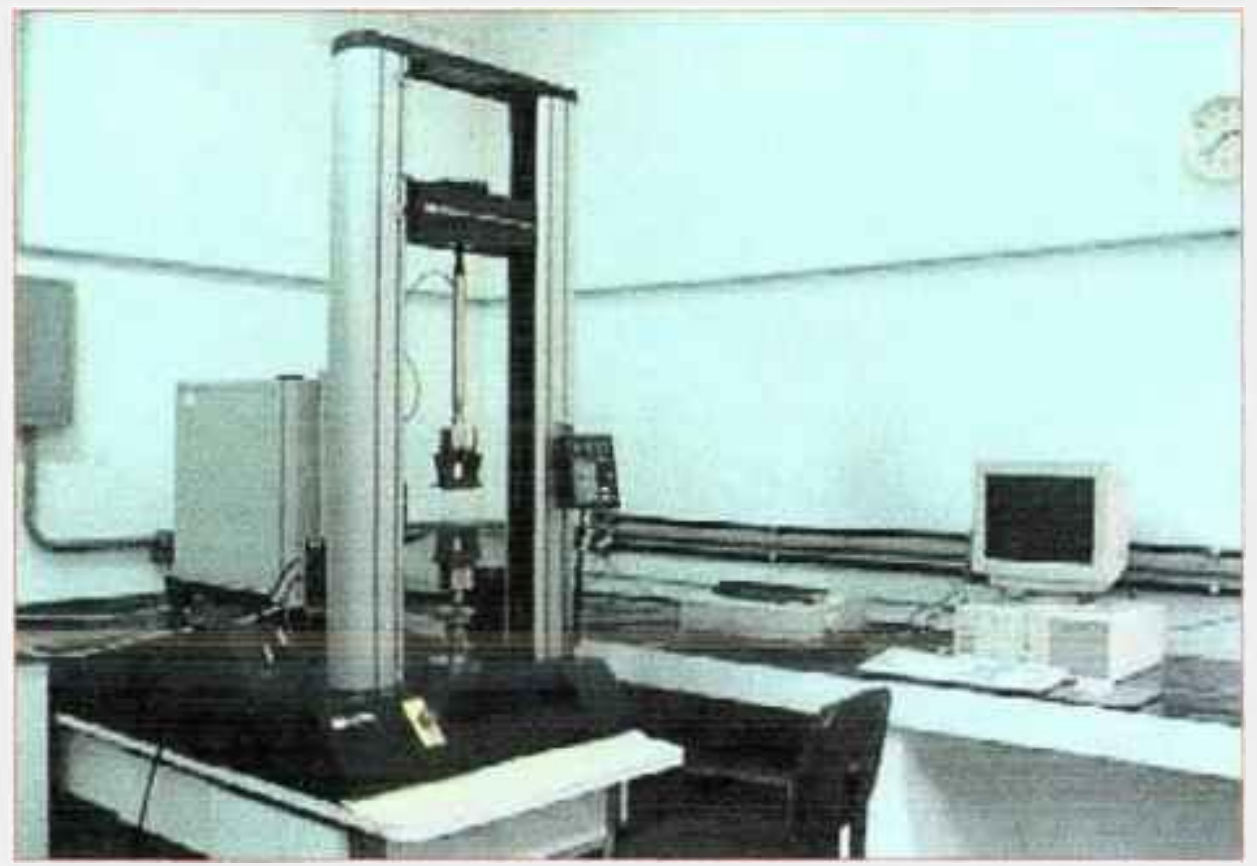

FIGURA 6 - Equipamento para ensaios de tração e deformação do CTR no IPEN 


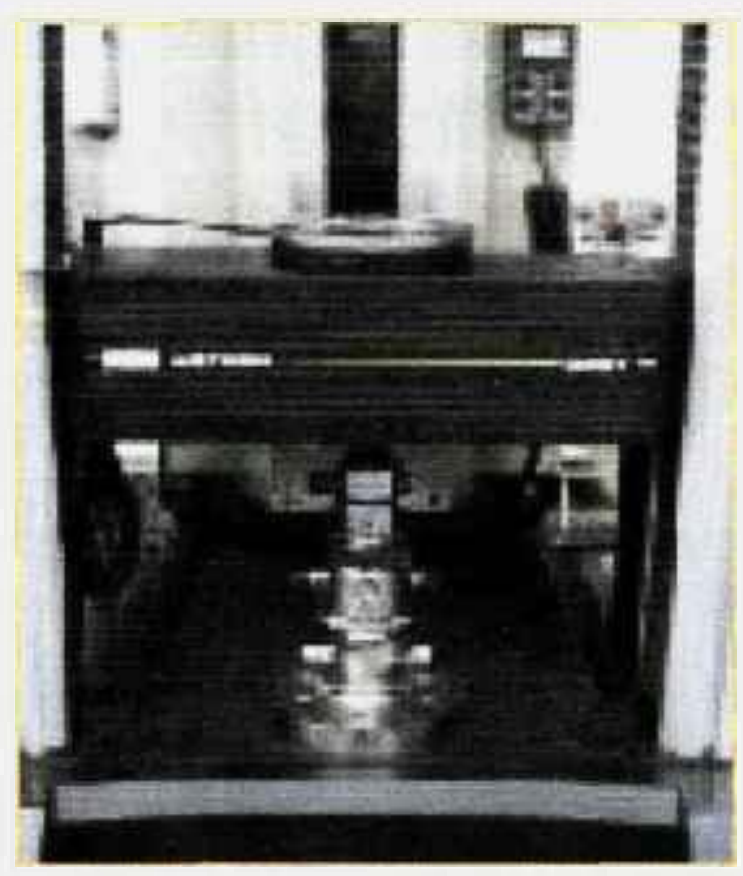

FIGURA 7-Acessórios para ensaios de compressão na Instron

\subsubsection{Deformação permanente por compressão}

Também conhecido como "Compression Set", mede a capacidade de o material retornar a sua espessura original após ser submetido a uma prolongada compressão em uma determinada temperatura. Como o material é comprimido durante muito tempo, o mesmo perde a capacidade de retornar a sua espessura inicial. Esta perda de resiliência (ou memória) pode diminuir parcialmente a capacidade do material em ser utilizado durante muito tempo como isolante térmico, acústico ou absorvedor de impacto. $\mathrm{O}$ método utilizado para verificar a deformação permanente por compressão seguiu a norma ASTM D 395-85, método B. Esta é uma propriedade importante para materiais utilizados como absorvedores de impacto como é caso da espuma em estudo As amostras com espessura inicial de $10 \mathrm{~mm}$ foram colocadas entre duas placas metálicas paralelas e sofreram uma compressão de $25 \%$ por um período de 24 horas (FIG. 8 e 9). Após este tempo, as amostras foram retiradas e após um período de 8 horas as suas dimensões foram novamente determinadas e a deformação permanente foi calculada utilizando a equação 7 . 


$$
C S=\left[\left(t_{0}-t_{i}\right) /\left(t_{0}-t_{n}\right)\right] \times 100
$$

em que:

$\mathrm{CS}=$ "Compression Set",

$\mathrm{t}_{0}=$ espessura inicial da amostra,

$t_{i}=$ espessura da amostra após o teste,

$t_{n}=$ espessura da barra espaçadora.

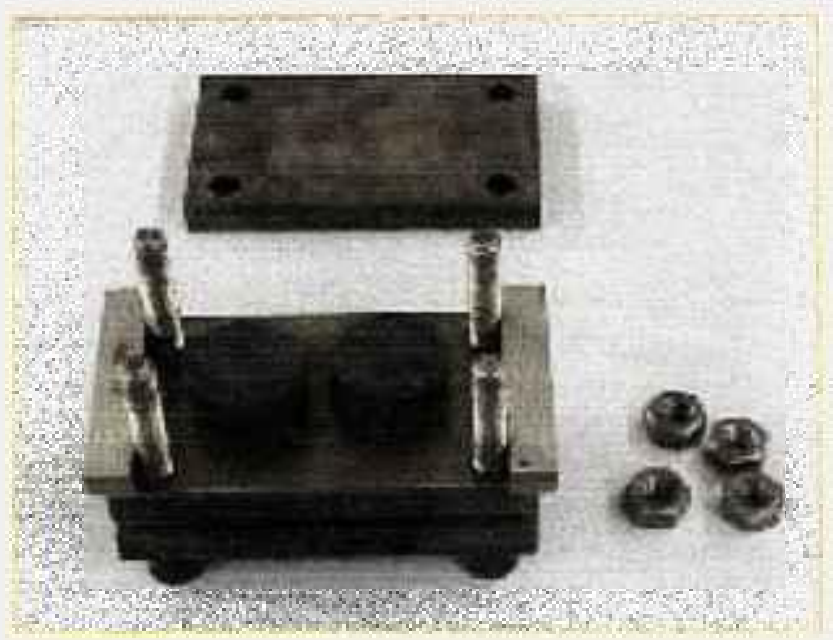

FIGURA 8 - Dispositivo para ensaio de deformação permanente por compressão 


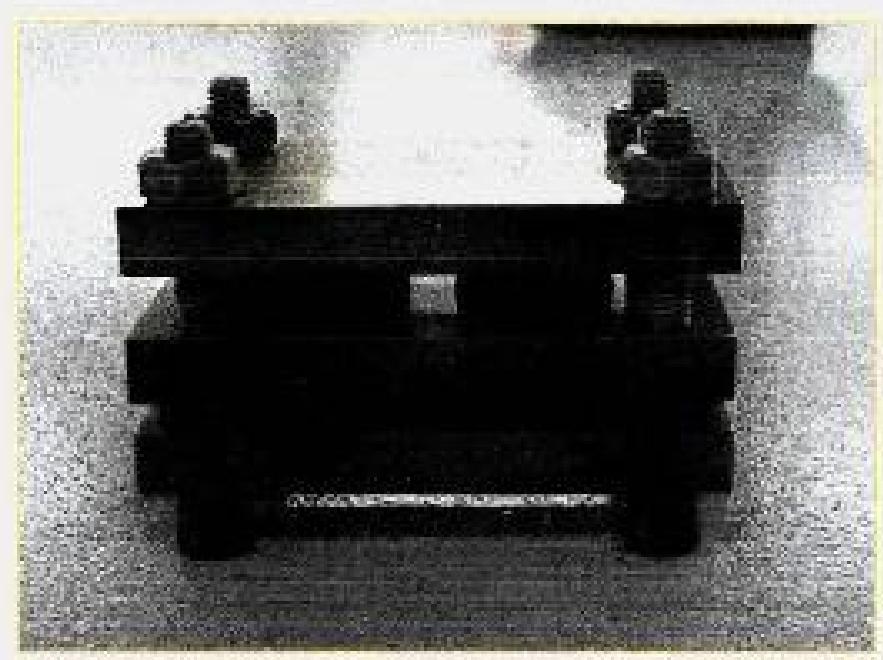

FIGURA 9-Amostra sob compressão

\subsection{Outros Ensaios}

\subsubsection{Determinação da Dureza Shore A}

Também foram realizados ensaios para determinar a dureza Shore A segundo a norma ASTM D 2240-02. Foram utilizadas 3 amostras para cada dose de radiação, segundo a norma. A dureza de um material depende de vários fatores internos e externos do material analisado. A dureza de materiais poliméricos depende, por exemplo, do estado de agregação, do nivel de interação molecular, da presença de ramificação e reticulação, da cristalinidade, da espessura da placa, entre outros. Por isso a dureza (rigidez) não é uma propriedade intrínseca ou absoluta. De forma geral, a dureza é a capacidade de o material resistir à penetração durante os ensaios de dureza.

\subsubsection{Resiliência}

A determinação da resiliência foi feita utilizando um resiliômetro Shore. A resiliência é determinada pela quantidade de energia devolvida após a deformação, por aplicação de uma tensão. É medida normalmente em percentual da espessura recuperada e fornece informações sobre o caráter elástico do material. Nas espumas flexíveis e elastômeros celulares, a resiliência é determinada pela quantidade de energia devolvida após o impacto do material com uma massa conhecida, sendo medida pelo ricochete resultante. Um material perfeitamente elástico tem uma resiliência de $100 \%$ e um perfeito absorvedor de $0 \%$. Para espumas flexíveis de baixa densidade foi aplicado um método simples, de acordo com a norma ASTM D 3574-01, no qual uma esfera de tamanho e peso padrão cai sobre a amostra da espuma, de uma altura padrão. Também, a quantidade de 
energia utilizada na deformação do material pode ser determinada pela massa da esfera e pela diferença das alturas inicial e final determinada pelo ricochete resultante (FIG. 10).

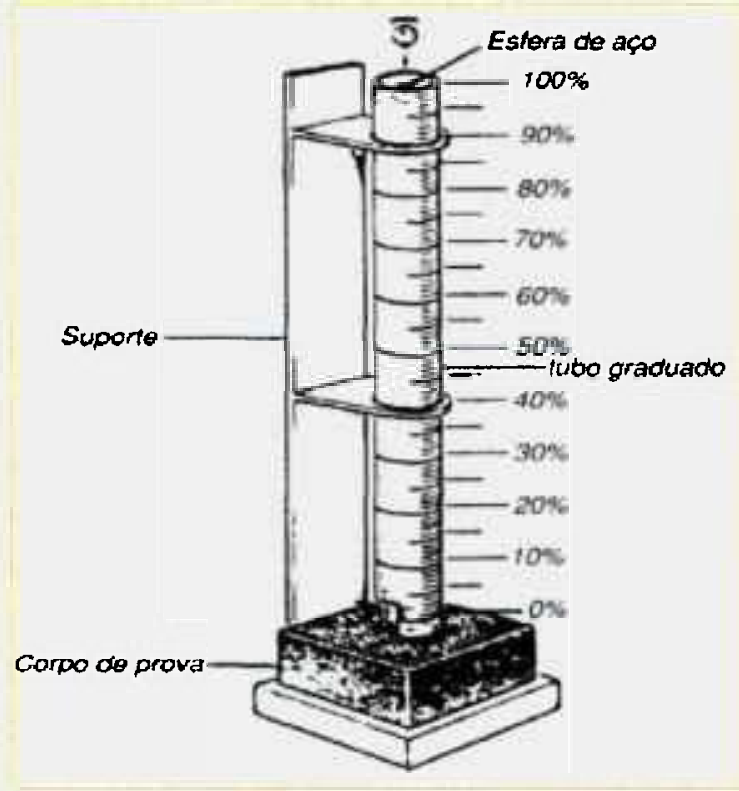

FIGURA 10 - Resiliômetro

\subsubsection{Microscopia eletrônica de varredura (MEV)}

As amostras para microscopia foram fraturadas em nitrogênio líquido e as superficies de fratura foram metalizadas com ouro. As análises morfológicas foram realizadas em microscópio eletrônico de varredura JEOL, Modelo JXA - 6400, do Centro de Tecnologia da Marinha em São Paulo - CTMSP. 


\section{RESULTADOS E DISCUSSÃO}

\subsection{Expansão térmica}

No processo de expansão térmica, para formação das espumas, as amostras com doses de 10,80 e 100 kGy não formaram espumas, pois durante a expansão, estas amostras entraram em colapso térmico, pois tanto a falta de reticulação como o excesso, inibem o crescimento das bolhas, desestabilizando o sistema de formação das espumas.

\subsection{Porcentagem de reticulação}

Na TAB. 2 são apresentados os resultados da fração gel ou porcentagem de reticulação de polietileno em diferentes doses de radiação e em amostras reticuladas com peróxidos.

TABELA 2 - Fração gel das espumas de LDPE reticulado com diferentes doses de radiação e com peróxido

\begin{tabular}{ccccccccc}
\hline Dose (kGy) & 10 & 20 & 30 & 40 & 50 & 60 & 80 & Peróxido \\
\hline $\begin{array}{c}\text { Porcentagem } \\
\text { de reticulação } \\
(\%)\end{array}$ & 23 & 34 & 48 & 59 & 65 & 72 & 79 & 74 \\
\hline
\end{tabular}

Na FIG. 11 é mostrado o gráfico de grau de reticulação de espumas de polietileno reticulado por feixe de elétrons a diferentes doses de radiação e por peróxido. 


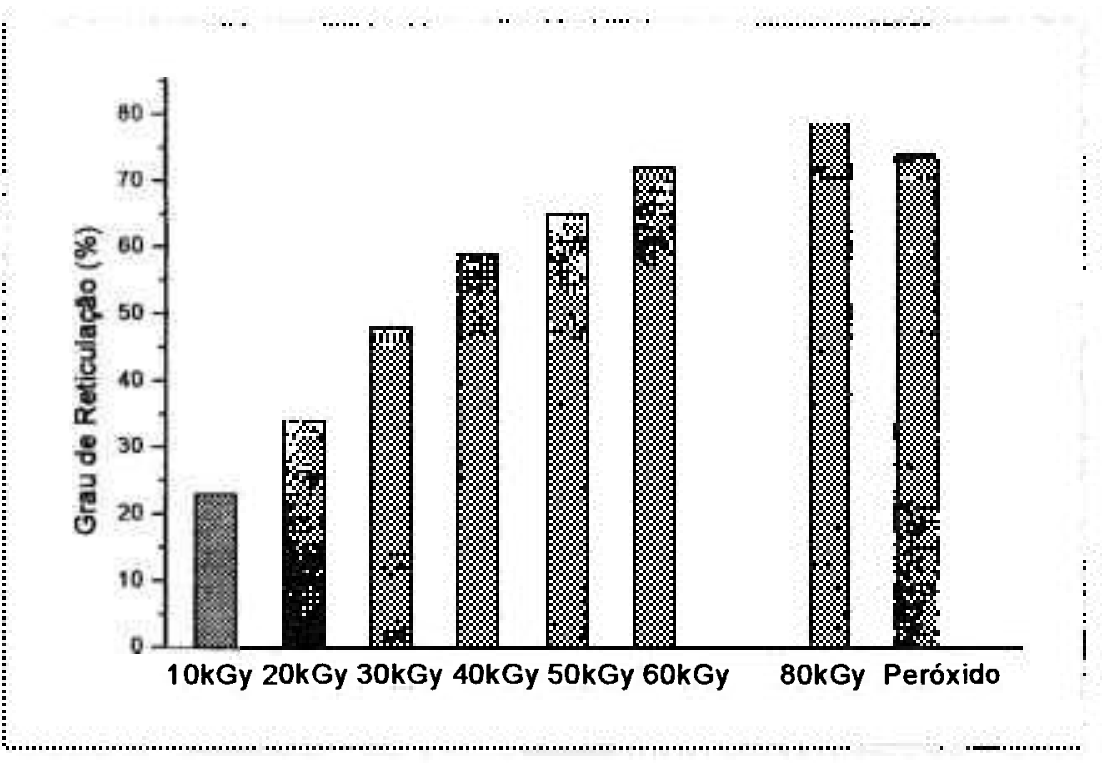

FIGURA 11 - Grau de reticulação de espumas de LDPE reticulado por feixe de elétrons a diferentes doses de radiação e por peróxido

A fração gel (porcentagem de polietileno reticulado) é definida como a fração do polímero não solúvel no xileno em ebulição. Ė importante determinar a porcentagem do polímero reticulado, pois o excesso de reticulação restringe a expansão da espuma, enquanto que a reticulação insuficiente resulta na ruptura das bolhas e consequentemente decréscimo nos valores das propriedades mecânicas. $\mathrm{O}$ aumento das ligações cruzadas ou reticulação é conseqüência da radiação em macromoléculas, que inicialmente formam radicais livres que podem se movimentar pela cadeia polimérica, gerando ligações cruzadas (interconexões dos macrorradicais formados). $\mathrm{O}$ polietileno irradiado com doses de 30 e $40 \mathrm{kGy}$ produziram espumas com superficie lisa e homogênea, enquanto que com 20 , 50 e $60 \mathrm{kGy}$, as espumas obtidas apresentaram superficie rugosa e células nãouniformes, pois, reticulação insuficiente bem como elevadas porcentagens de reticulação inibem a formação da espuma. 


\subsection{Estabilidade térmica das espumas}

Na TAB. 3 são apresentados os resultados das temperaturas de degradação do polietileno de amostras não espumadas.

TABELA 3 - Temperaturas de degradação do LDPE não espumado em função da dose de radiação

\begin{tabular}{cc}
\hline Dose & $\begin{array}{c}\text { Temperatura de } \\
\text { degradação do } \\
\text { PGy) }\end{array}$ \\
\hline 0 & 455 \\
20 & 455 \\
40 & 458 \\
60 & 454 \\
80 & 451 \\
\hline
\end{tabular}

Conforme os resultados apresentados na TAB. 3, a partir de $60 \mathrm{kGy}$, a temperatura de decomposição do polímero diminuiu, indicando uma possível degradação do mesmo. As espumas obtidas com doses de 20 e $60 \mathrm{kGy}$ apresentaram superficie heterogênea, e com células não uniformes. As espumas obtidas com dose de $40 \mathrm{kGy}$ apresentaram superficie lisa, boa aparência e espessura uniforme como já foi dito anteriormente.

$\mathrm{Na}$ TAB. 4 são apresentados os resultados da variação das dimensões das espumas de LDPE que foram expostas ao calor para verificação da estabilidade térmica. 
TABELA 4 - Variação das dimensões para verificação da estabilidade térmica das espumas de LDPE reticulado por radiação e por peróxido

\begin{tabular}{cc}
\hline $\begin{array}{c}\text { Dose } \\
(\mathrm{kGy})\end{array}$ & $\begin{array}{c}\text { Variação das } \\
\text { dimensões } \\
(\%)\end{array}$ \\
\hline 20 & 3,14 \\
30 & 1,32 \\
40 & 1,38 \\
60 & 3,67 \\
\hline Peróxido & 2,66 \\
\hline
\end{tabular}

Na FIG. 12 é mostradò o comportamento das espumas de LDPE reticulado por feixe de elétrons a diferentes doses e por peróxido para verificação da estabilidade térmica.

FIGURA 12 - Comportamento das espumas de LDPE reticulado por radiação a diferentes doses e por peróxido, para verificação da estabilidade térmica 
A partir dos resultados apresentados na TAB. 4, as espumas formadas a partir de LDPE reticulado com doses de radiação de 30 e 40 kGy apresentaram menor variação das dimensões quando expostas ao calor. $\mathbf{O}$ grau de reticulação afeta as propriedades mecânicas e térmicas do material polimérico, sendo que quanto mais reticulado, mais rígido e mais estável às variações de temperatura, pela formação da rede tridimensional. As espumas formadas a partir de LDPE irradiado com doses de $20 \mathrm{kGy}$ e $60 \mathrm{kGy}$ apresentaram grande variação quando comparadas com as de 30 e 40 kGy (FIG. 12). Este comportamento indica que a reticulação aumenta a estabilidade das espumas. Porém, espumas de LDPE reticulado com doses de $60 \mathrm{kGy}$, indicam que pode está ocorrendo o predomínio da cisão sobre a reticulação, acelerando o aumento da variação das dimensões das espumas quando expostas ao calor.

\subsection{Ensaios de resistência à tração}

$\mathrm{Na}$ TAB. 5 são apresentados os resultados das propriedades mecânicas de resistência à tração e deformação na ruptura de amostras de espumas de LDPE reticulado com diferentes doses de radiação e com peróxido, submetidas ao envelhecimento térmico durante 24 horas a temperatura de $70^{\circ} \mathrm{C}$, utilizando um forno com circulação forçada de ar. Também são apresentados nesta Tab. 5 os resultados das amostras envelhecidas termicamente e as não envelhecidas, bem como os resultados de uma amostra de espuma obtida pelo processo convencional de reticulação por peróxido. 
TABELA 5 - Resistência à tração e alongamento na ruptura de amostras de espuma de LDPE reticulado por radiação a diferentes doses e por peróxido, envelhecidas e não envelhecidas termicamente

\begin{tabular}{ccccc}
\hline $\begin{array}{l}\text { Dose } \\
(\mathrm{kGy})\end{array}$ & \multicolumn{2}{c}{ Resistência à tração máxima } & \multicolumn{2}{c}{$\begin{array}{c}\text { Deformação } \\
(\mathrm{MPa})\end{array}$} \\
\cline { 2 - 5 } & $\begin{array}{l}\text { Não } \\
\text { envelhecidas }\end{array}$ & Envelhecidas & $\begin{array}{l}\text { Não } \\
\text { envelhecidas }\end{array}$ & Envelhecidas \\
\hline 20 & $0,73 \pm 0,10$ & $0,55 \pm 0,05$ & $363,12 \pm 18,25$ & $192,07 \pm 47,81$ \\
30 & $0,82 \pm 0,01$ & $0,81 \pm 0,03$ & $324,56 \pm 14,83$ & $285,17 \pm 11,39$ \\
40 & $1,04 \pm 0,02$ & $0,92 \pm 0,12$ & $316,67 \pm 12,42$ & $273,55 \pm 37,49$ \\
60 & $1,19 \pm 0,07$ & $1,03 \pm 0,08$ & $260,17 \pm 18,36$ & $242,20 \pm 21,68$ \\
\hline Peróxido & $0,87 \pm 0,04$ & $0,84 \pm 0,05$ & $391,43 \pm 11,18$ & $373,76 \pm 19,54$ \\
\hline
\end{tabular}

Nas Fig. 13 e 14 são mostrados os comportamentos da resistência à tração e alongamento na ruptura de espumas de LDPE reticulado por radiação e por peróxido, não envelhecidas e envelhecidas termicamente. 


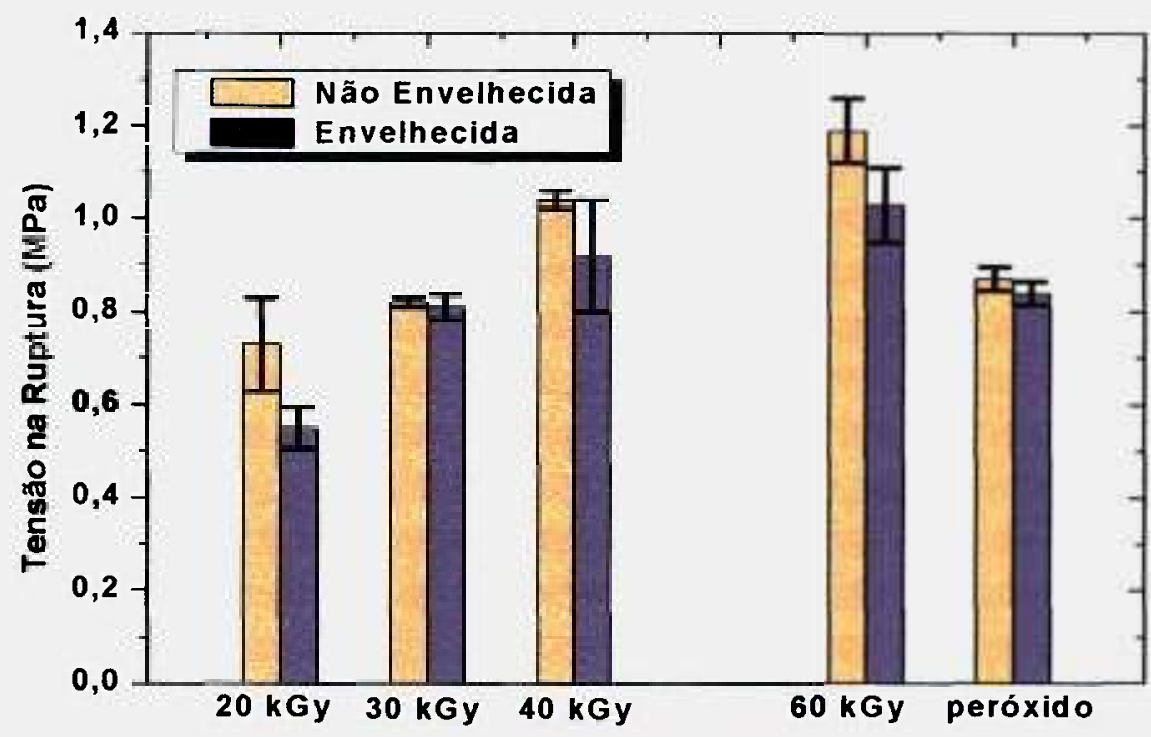

FIGURA 13 - Comportamento da resistência à tração na ruptura das espumas de LDPE reticulado por radiação e por peróxido, envelhecidas e não envelhecidas

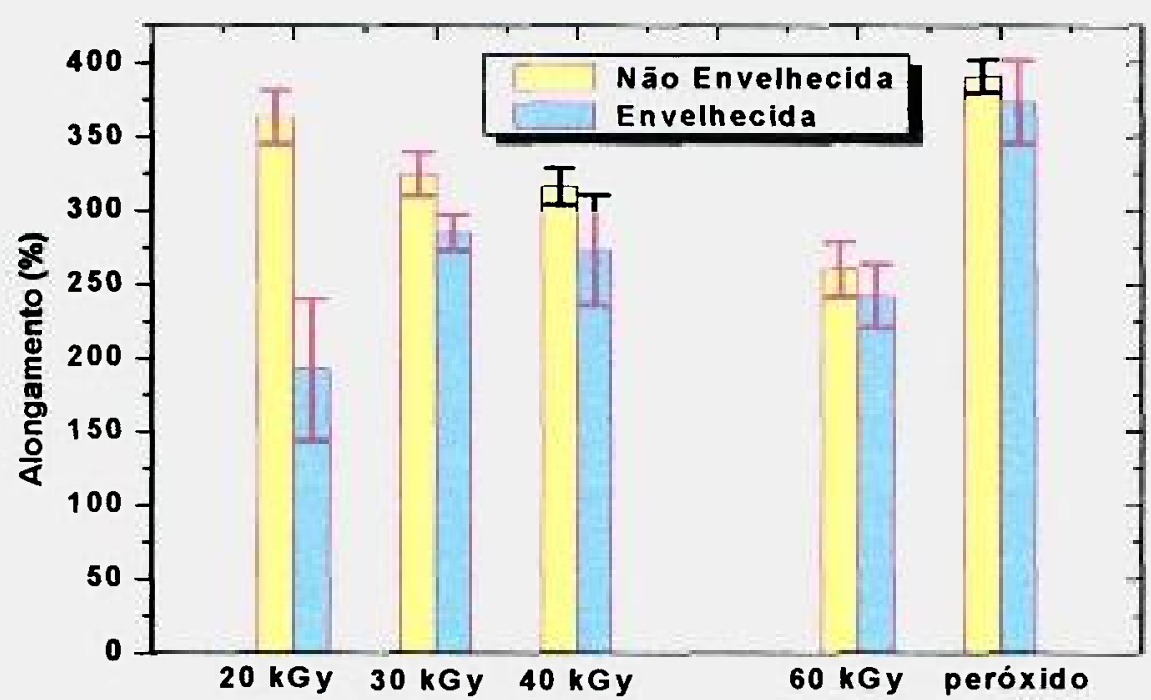

FIGURA 14 - Comportamento da deformação na ruptura das espumas de LDPE reticulado por radiação e por peróxido, envelhecidas e não envelhecidas

Conforme os resultados apresentados na TAB. 5, foi observado o incremento da resistência à tração e redução da taxa de deformação com o aumento da dose de radiação. Este comportamento indica que com o aumento da dose de radiação, ocorrem mais 
ligações cruzadas (reticulação), aumentando a rigidez do material e, portanto, elevando a resistência à tração na ruptura e reduzindo a deformação na ruptura. Foi observada a diminuição mais acentuada na resistência à tração e no alongamento na amostra irradiada com dose de $20 \mathrm{kGy}$ e envelhecida termicamente, indicando que quanto menor o grau de reticulação, maior a degradação térmica.

\subsection{Ensaios de resistência à compressão}

Na TAB. 6 são apresentados os resultados das propriedades mecânicas de compressão, das amostras de LDPE reticulado por radiação e por peróxido, envelhecidas e não envelhecidas termicamente as quais foram submetidas a redução de $40 \%$ e de $60 \%$ da sua espessura inicial.

TABELA 6 - Resistência à compressão (40\% e 60\%) de amostras de espumas de LDPE reticulado por radiação a diferentes doses e por peróxido, envelhecidas e não envelhecidas termicamente em função da dose de radiação

\begin{tabular}{ccccc}
$\begin{array}{c}\text { Dose } \\
(\mathrm{kGy})\end{array}$ & \multicolumn{2}{c}{$\begin{array}{c}\text { Carga Compressiva }-40 \% \\
(\mathrm{~N})\end{array}$} & \multicolumn{2}{c}{$\begin{array}{c}\text { Carga Compressiva }-60 \% \\
(\mathrm{~N})\end{array}$} \\
\cline { 2 - 5 } & Não envelhecidas & Envelhecidas & Não envelhecidas & Envelhecidas \\
\hline 20 & $104,9 \pm 17,6$ & $76,4 \pm 7,5$ & $344,1 \pm 51,6$ & $222,4 \pm 53,4$ \\
30 & $134,2 \pm 12,4$ & $111,1 \pm 7,1$ & $390,3 \pm 50,1$ & $250,9 \pm 43,2$ \\
40 & $179,1 \pm 27,4$ & $117,1 \pm 24,9$ & $442,8 \pm 48,1$ & $231,3 \pm 21,1$ \\
50 & $149,7 \pm 10,3$ & & $376,1 \pm 35,6$ & \\
\cline { 5 - 6 } 60 & $152,1 \pm 12,4$ & $108,3 \pm 14,5$ & $290,5 \pm 31,2$ & $132,7 \pm 7,6$ \\
\hline Peróxido & $133,5 \pm 3,4$ & $125,8 \pm 17,3$ & $297,6 \pm 45,2$ & $222,1 \pm 64,1$ \\
\hline
\end{tabular}

Nas Fig. 15 e 16 são apresentados os gráficos de resistência à compressão das espumas de LDPE reticulado por radiação e por peróxido, não envelhecidas e envelhecidas termicamente, submetidas à carga compressiva de $40 \%$ e $60 \%$ de suas espessuras iniciais. 


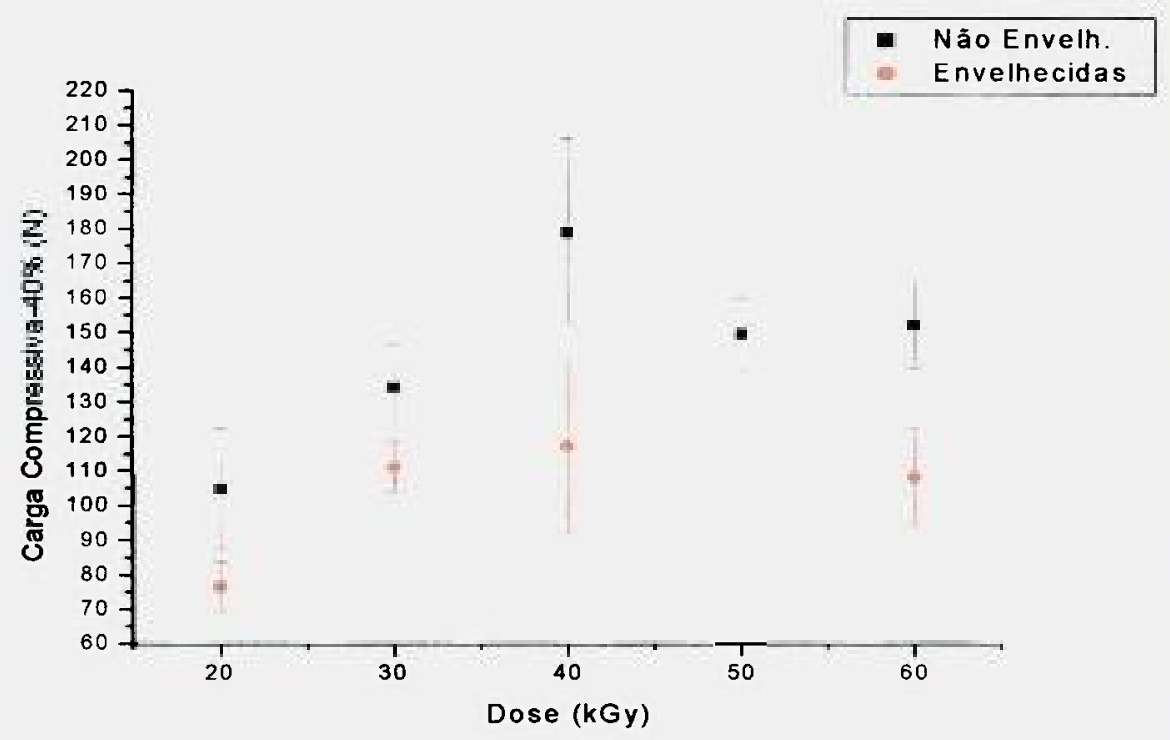

FIGURA 15 - Resistência à compressão (40\%) das espumas de LDPE reticulado envelhecidas e não envelhecidas em função da dose de radiação

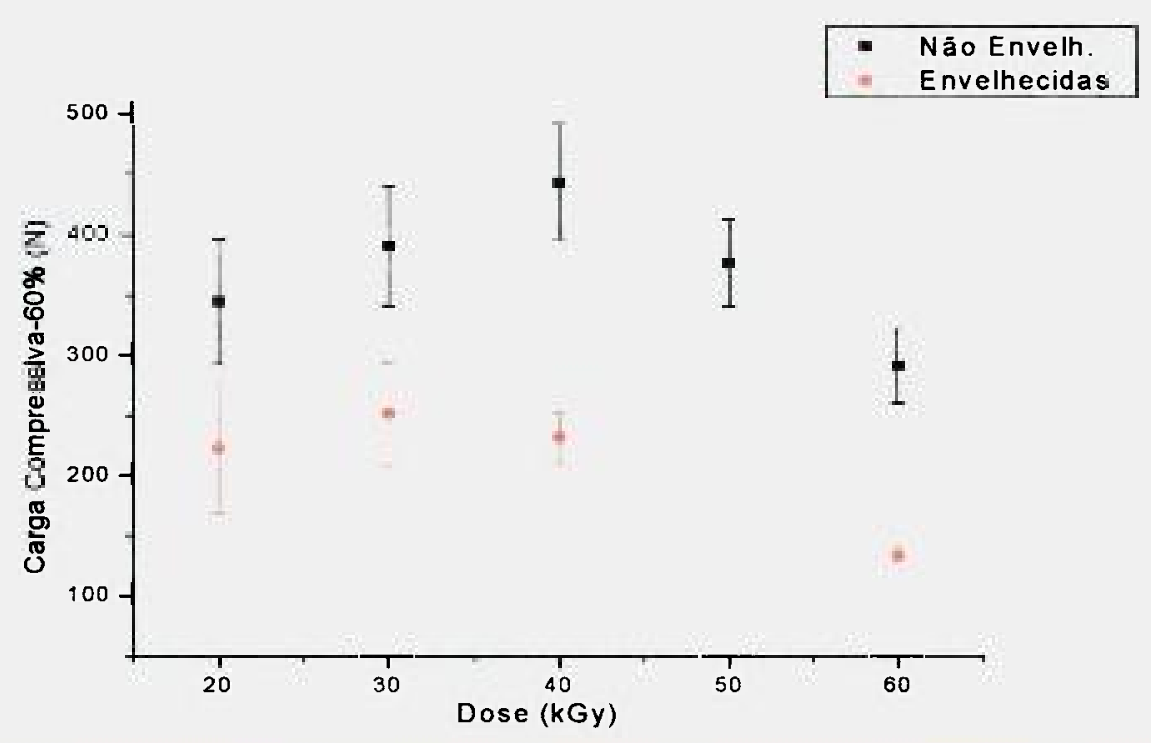

FIGURA 16 - Resistência à compressão (60\%) das espumas de LDPE reticulado envelhecidas e não envelhecidas em função da dose de radiação

Pelos resultados apresentados na TAB. 6 e mostrados nas FIG. 15 e 16, observa-se que com o aumento da dose de radiação, e conseqüente aumento do grau de reticulação, as espumas apresentaram aumento na resistência à deformação causada por 
compressão, necessária para comprimir $40 \%$ e $60 \%$ da espessura inicial. As amostras de 50 e $60 \mathrm{kGy}$ apresentaram uma diminuição na resistência à compressão, indicando uma possível degradação das espumas, causada pela radiação do LDPE. Após a aplicação da carga compressiva, as amostras de espumas retornaram ao tamanho original, caracterizando uma capacidade de absorção de carga boa. Também a partir dos resultados apresentados na TAB. 6 observa-se que as amostras envelhecidas apresentaram uma queda na resistência à compressão.

Esta diminuição ocorreu provavelmente devido ao processo de degradação térmica causado pela exposição das amostras ao calor. Com a alteração das propriedades mecânicas das espumas envelhecidas termicamente observa-se a ruptura das membranas das células fechadas, causadas pela expansão do ar dentro das células. Esta ruptura das membranas das células geralmente ocorrem durante o estágio inicial da aplicação da carga.

\subsection{Determinação da dureza}

Na TAB. 7 são apresentados os resultados de dureza das espumas de LDPE reticulado por radiação e por peróxido.

TABELA 7 - Dureza de amostras de espumas de LDPE reticulado por radiação a diferentes doses e por peróxido

\begin{tabular}{cc}
\hline $\begin{array}{c}\text { Dose de radiação } \\
(\mathrm{kGy})\end{array}$ & Dureza (Shore A) \\
\hline 20 & 24 \\
30 & 28 \\
40 & 30 \\
60 & 33 \\
\hline Peróxido & 29 \\
\hline
\end{tabular}

Os resultados mostraram um aumento da dureza com o aumento da dose de radiação. Este comportamento indica o aumento do grau de reticulação do material, devido as forças intermoleculares, resultando em um valor maior de dureza. As 
amostras reticuladas por peróxido, apresentaram um valor próximo das espumas obtidas pelo processo de irradiação do LDPE nas doses de 30 e $40 \mathrm{kGy}$. As espumas com dose de $60 \mathrm{kGy}$, apresentaram uma dureza maior, porém, como já visto nas propriedades de resistência à tração e à compressão, elas perdem suas propriedades mecânicas, e também já começam a apresentar uma superficie rugosa e espessura não uniforme.

\subsection{Determinação da resiliência}

Na TAB. 8 são apresentados os resultados da resiliência de espumas de LDPE reticulado por radiação e por peróxido.

TABELA 8 - Resiliência de amostras de espumas de LDPE reticulado por radiação a diferentes doses e por peróxido

\begin{tabular}{cc}
$\begin{array}{c}\text { Dose de radiação } \\
(\mathrm{kGy})\end{array}$ & $\begin{array}{c}\text { Resiliência } \\
(\%)\end{array}$ \\
\hline 20 & 30 \\
30 & 31 \\
40 & 33 \\
60 & 35 \\
\hline Peróxido & 32 \\
\hline
\end{tabular}

Os resultados mostraram um pequeno aumento da resiliência com o aumento da dose de radiação. Quanto mais próximo de $0 \%$, a espuma é caracterizada como um material absorvedor de impacto. As espumas obtidas com doses de 20 a 40 kGy estão com uma resiliência mais próxima das obtidas por peróxidos. 


\subsection{Microscopia eletrônica de varredura}

Nas FIG. 17, 18, 19 e 20, referentes aos ensaios de microscopia eletrônica de varredura são apresentadas a estrutura celular das espumas obtidas a partir do LDPE reticulado a diferentes doses de radiação.

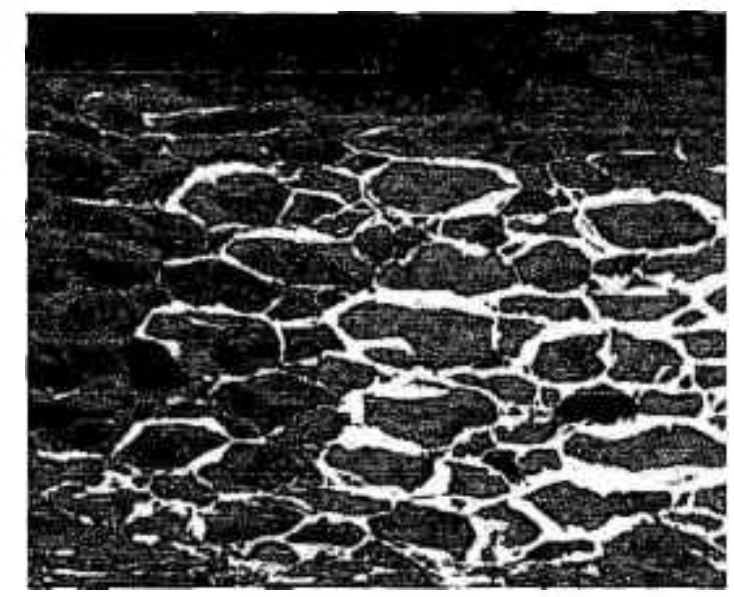

FIGURA 17 - Micrografia de espuma de LDPE reticulado por radiação com dose de 20 kGy (Ampliação: $15 \mathrm{X}$ )

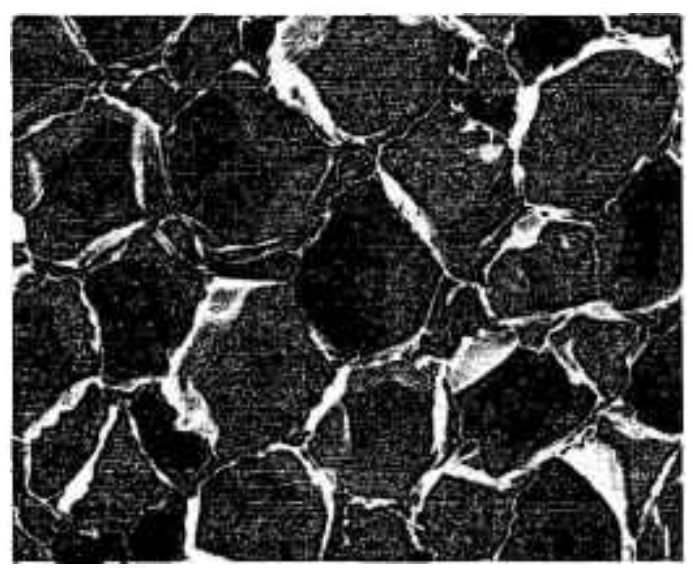

FIGURA 18 - Micrografia de espuma de LDPE reticulado por radiação com dose de 30 kGy (Ampliação: $30 \mathrm{X}$ ) 


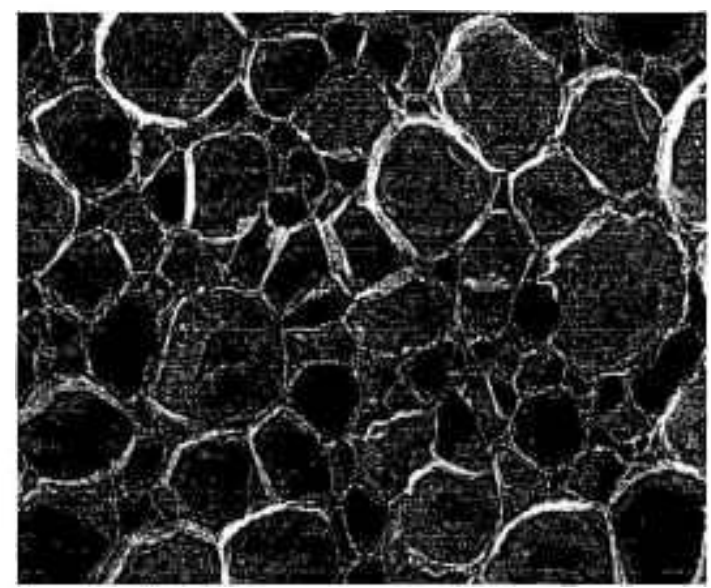

FIGURA 19 - Micrografia de espuma de LDPE reticulado por radiação com dose de 40 kGy (Ampliação: 30 X)

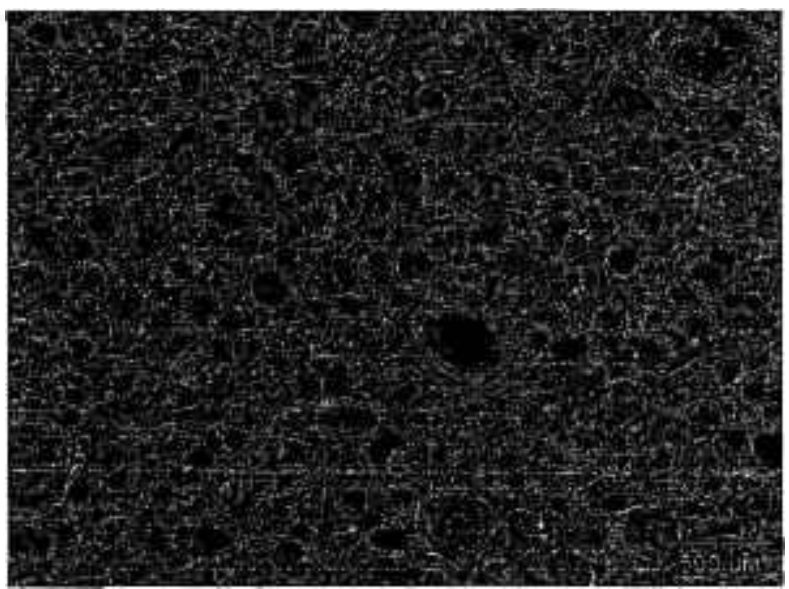

FIGURA 20 - Micrografia de espuma de LDPE reticulado por radiação com dose de 60 kGy (Ampliação: 30 X)

Como pode ser observado nas FIG. 17 a 20, as espumas têm uma estrutura celular fechada, provavelmente por causa das ligações cruzadas, o que ajuda a diminuir a ruptura das células durante o processo de expansão. As espumas de polietileno reticulado com doses de 20 e 60 kGy apresentaram uma superficie rugosa, e heterogênea. $\mathrm{O}$ crescimento das células para formação das espumas, é prejudicado pela baixa reticulação, bem como pelo excesso. Em ambos os casos, ocorrem o chamado colapso térmico. $O$ que provoca a ruptura das membranas das células, diminuindo a resistência das espumas quando submetidas à compressão. 


\subsection{Ensaios de resistência à deformação permanente por compressão}

Os valores para a deformação permanente à compressão (DPC) são apresentados na TAB. 8, onde se observa valores elevados para doses de $20 \mathrm{kGy}$, provocado pela falta de reticulação. Com o aumento da dose e conseqüente aumento das ligações cruzadas, as espumas com 30 e $40 \mathrm{kGy}$, apresentaram uma melhora no seu desempenho. A partir de $60 \mathrm{kGy}$, as espumas já apresentaram uma elevada deformação permanente, caracterizando a degradação do LDPE, causada pela radiação.

TABELA 8 - Deformação permanente por compressão (DPC) de espumas de LDPE reticulado por radiação a diferentes doses e por peróxido

\begin{tabular}{cc}
\hline $\begin{array}{c}\text { Dose de Radiação } \\
(\mathrm{kGy})\end{array}$ & $\begin{array}{c}\text { DPC } \\
(\%)\end{array}$ \\
\hline 20 & 23,70 \\
30 & 13,23 \\
40 & 9,15 \\
50 & 12,38 \\
60 & 19,73 \\
\hline Peróxido & 15,26 \\
\hline
\end{tabular}

Na FIG. 21 é mostrado o comportamento das espumas de LDPE reticulado por radiação e por peróxido para verificação da deformação permanente por compressão. 


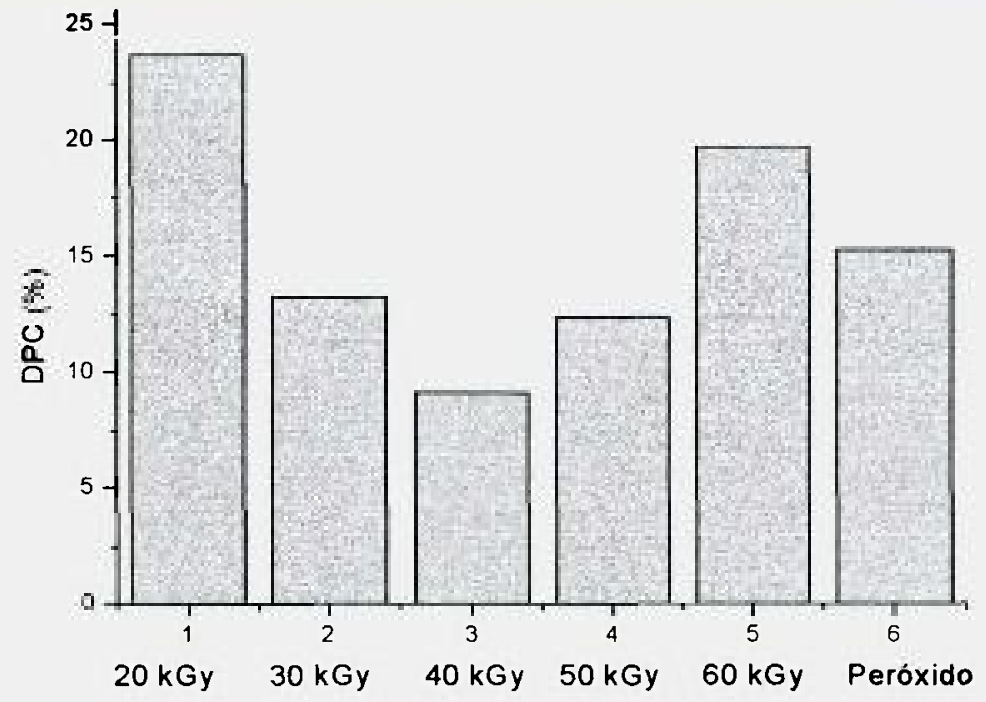

FIGURA 21 - Comportamento das espumas de LDPE reticulado por radiação e por peróxido para verificação da deformação permanente por compressão 


\section{CONCLUSÕES}

A reticulação do polietileno tem grande influência durante a obtenção das espumas, pois interfere na formação das bolhas geradas durante o processo de expansão que ocorre com a decomposição do agente expansor.

Foram obtidas espumas com boas propriedades mecânicas e térmicas quando o polietileno foi reticulado com doses de 30 e $40 \mathrm{kGy}$.

As espumas obtidas com doses de 20, 50 e $60 \mathrm{kGy}$, apresentaram superficie rugosa e com estrutura celular heterogênea.

Os resultados de análise térmica mostraram que a partir de $60 \mathrm{kGy}$ a temperatura de decomposição do polímero diminuiu, indicando uma possível degradação do mesmo.

Também foi observado que durante o processo de expansão, as amostras de PE irradiado com doses de 10 e 80 kGy não formaram espuma, indicando a ocorrência do colapso térmico, causado pela degradação do material.

As espumas de polietileno reticulado pelo processo de irradiação com feixe de elétrons, apresentaram superficie mais lisa e homogênea, quando comparadas com as reticuladas pelo processo químico, utilizando peróxido como agente reticulante.

As espumas obtidas com polietileno irradiado com dose de $30 \mathrm{kGy}$ apresentaram uma menor variação dimensional quando submetidas ao aquecimento de $70^{\circ} \mathrm{C}$ por 24 horas, indicando uma boa estabilidade térmica.

Nos testes de resistência à tração e compressão, também as espumas com doses de $30 \mathrm{kGy}$ apresentaram pequena variação quando as mesmas foram submetidas ao ensaio de envelhecimento térmico. 
Com base no trabalho realizado concluiu-se que as espumas obtidas com doses de $30 \mathrm{kGy}$ foram as que apresentaram o melhor comportamento em relação as propriedades estudadas. Assim sendo, pode-se irradiar o LDPE com doses menores, ou seja, de $30 \mathrm{kGy}$, para formação de espuma, diminuindo os custos do produto final. 


\section{SUGESTÕES PARA TRABALHOS FUTUROS}

Análise do custo na utilização da radiação ionizante para obtenção de espumas de polietileno reticulado. Fazer uma comparação do custo entre as espumas obtidas de polietileno reticulado por radiação e por peróxido.

Estudo dos efeitos da radiação ionizante sobre o agente expansor utilizado na obtenção de espumas de polietileno.

Estudo da degradação por irradiação das espumas de polietileno.

Estudo de espumas utilizadas como isolantes elétricos 


\section{REFERÊNCIAS BIBLIOGRÁFICAS}

ADEM, E.; AVALOS-BORJA, M.; CARRILO, D.; VASQUEZ, M.; SANCHES, E.; CARREON, M. P. e BURILLO, G. Crosslinking of recycled polyethylene by gamma and electron beam irradiation. Radiat. Phys. Chem., v. 53, n. 1/6, p. 171-1 76, 1998.

ADEM, E.; BURRILLO, G., DAKIN, V. e VASQUEZ, M. Promoting polyethylene foams by irradiation crosslinking in Mexico. Radiat. Phys. Chem., v. 46, n. 4/6, p. 937-940, 1995.

BENNING, C. J. Plastics foams. New York, N. Y. Wiley-Interscience, 1986.

BOLT, R. O.; CARROL, J, G. Radiation effects on polymers. London: Elsevier Applied Science, 1991.

CARDOSO, E. C. L.; LUGÃO, A. B.; ANDRADE E SILVA, L. G. Crosslinked polyethylene foams, via EB radiation. Radiat. Phys. Chem., v. 52, n. 1/6, p. 197$200,1998$.

CARON, L. E. Correlação entre o comportamento mecânico, elétrico, e térmico e o teor de negro de fumo em PEBD reticulado (XLPE). 1996. Dissertação (Mestrado) - Universidade Federal de São Carlos, São Paulo.

CELINA, M.; GEORGE, G. A. Characterisation and degradation studies of peroxide and silane crosslinked polyethylene. Polym. Degrad. Stab. v.48, p. 297-312, 1995

CHAPIRO, A.; LEGRIS, C. Gel formation in the radiolysis of poly(NVinylpyrrolidone) solutions. Radiat. Phys. Chem., v. 28, n. 2, p. 143-144, 1986.

CHARLESBY, A. Crosslinking of polyethylene by pile radiation. Proc. R. Soc., London, 1952.

CHODAK, I. Properties of crosslinked polyolefin-based materials. J. Prog. Polym. Sci., v. 20, p. 1165-1199, 1995.

CORISHI, P. J. Radiation effects on polymers radiation process. In: CORISHI, P., J.; Polymer processing \& applications. New York. Pergamon, 1992. p. 581-597.

CLOUGH, R. L; SHALABY, S. W. Radiation effects on polymers. Washington, D. C., American Chemical Society, 1991. 
DANAEI, M.; SHEIKHY, N. Radiation crosslinked foam: preparation and properties. J. Cell. Plast., v. 41, n. 6, p. 551-562, 2005.

ELF ATOCHEM NORTH AMERICA, Inc. Organic Peroxides. Philadelphia, 1992.

EPSTEIN, P. S.; PLESSET, M., S. On the stability of gas bubbles in liquid-gas solutions. J. Chem. Phys., v. 18, p. 1505-1522, 1950.

FRISCH, K. C. History of science and technology of polymeric foams. J. Macromol. Sci-Chem., v. 15, n. 6, p. 1089-1112, 1981.

GENT, A. N.; TOMPKINS, D. A. Nucleation and growth of gas bubble in elastomers. J. Appl. Phys., v. 40, p. 2520-2528, 1969.

GRUENWALD, G. Chemical properties of polymeric materials. In:

GRUENWALD, G.; Plastics. How structure determines properties. Munich: Hanser, 1993. Cap. 10, p. 235-248.

HANSEN, R. H.; MARTIN, W. Novel methods for the production of foamed polymers 2: nucleation of dissolved gas by finely-divided metals. J. Polym. Sci. part B 3, p. 325-346, 1965.

KIM, D. W. e KIM, S. K. Electron beam irradiation of noncrosslinked LDPE-EVA foam. J. Cell. Plast., v.38, p.471-496, 2002.

KIRCHER, $\mathrm{K}$. Chemical reactions in plastics processing. Munich: Carl Hanser Verlag, 1987. p. 153.

KLEMPNER, D; ; FRISCH, K, C. Handbook of polymeric foams and foam technology. New York, N. Y.:Hanser Publishers, 1991.

LIU, I-C.; CHUANG, C.-K.; TSIANG, R. C.-C. Foaming of electron-beam irradiated LDPE blends containing recycled polyethylene foam. J. Polym. Res., v. 11, p. 149$159,2004$.

MARK, J. E. Physical properties of polymers handbook. New York, N. Y.: AIP Press, 1996. p. 409.

O'DONNEL, J. H.; SANGSTER, B. Monomers and polymers. In: Principles of radiation chemistry, London: E. Arnold, 1970. Cap. 8, p. 113-124. 
PARK, C. P. Polyolefin foam In: KLEMPNER, D.; FRISCH, K. C. Handbook of polymeric foams and foam technology. New York, N. Y.: Hanser Publishers, 1991. p. $187-201$.

RADO, R. Preparation of crosslinked polyethylene compounds. Int. Polym. Sci. Tech., v. 20, n.7, p. 78-82, 1993.

ROSS, R. K. Scientific and technical reports. n.8, p. 209, 1990.

RUBENS, L. C.; GRIFFIN, J. D. U.S. Patent. 3067 147, Process of foaming and extruding polyethylene using 1,2-dichlorotetrafluoroethane as the foaming agent. 1962.

SHUTOV, F. A. Cellular structure and properties of foamed polymers. In: KLEMPNER, D.; FRISCH, K. C. Handbook of polymeric foams and foam technology. New York, N. Y.: Hanser Publishers, 1991. p. 19-25.

SPINKS, J. W. T. An introduction to radiation chemistry. 3a. ed. New York, N. Y.: John Wiley Sons, Inc., 1990.

STEWART, C. W. A study of the dynamics of bubble growth in thermoplastic elastomers. J. Polym. Sci. part A, v. 28, p. 937-947, 1970.

WU, S. Y.; XU, J. Y. Polymeric foams. Publication of chemical industry in China. 1999.

YANG, C.-T.; LEE, S.-T. Dimensional stability analysis of foams based on LDPE and ethylene-styrene interpolymer blends. J. Cell. Plast., v.39, p. 59-69, 2003.

ZHANG, Z. A study of ultra-high-molecular-weight polyethylene (UHMWPE) foams. 2001. Dissertação (Mestrado) - Faculté des Sciences et de Genie Universitié Laval, Québec. 